\title{
From broadband horizontal to effective in-plane irradiation: A review of modelling and derived uncertainty for PV yield prediction
}

\author{
R. Moretón , E. Lorenzo , A. Pinto , J. Muñoz , L. Narvarte
}

\begin{abstract}
A B S T R A C T
This article presents an analysis on irradiance modelling and its impact on energy estimation uncertainty. In particular, the calculation of the effective in-plane irradiance from broadband horizontal irradiance is assessed. Thirty-one models for irradiance distribution, decomposition, transposition and spectral correction have been considered. The simulation results have been compared with experimental records obtained during up to three years in 19 locations of the Mediterranean belt with static and tracking systems. Models performance has been evaluated in terms of hourly to yearly weighted errors and frequency distribution similarity. Finally, some bestperforming model combinations have been selected.
\end{abstract}

\section{Introduction}

Long-term energy estimations are a key step to determine the feasibility of a photovoltaic (PV) project [1-3]. They depend to a large extent on the calculation of the operating conditions, mainly on the effective in-plane irradiation [4-7]. When lacking on-site measurements a common practice is to turn to available solar radiation databases. These are sometimes provided in terms of hourly broadband horizontal values, $G(0)$, so that the energy yield prediction requires converting it into effective in-plane values, $G^{\text {ef }}$. This is typically addressed through a sequence of three different steps. First, decomposing the global horizontal irradiation into its direct and diffuse components; second, transposing them from the horizontal to the array plane; third, reaching the effective values after by correcting the angular and spectral responses of the PV module. More often, solar radiation databases are given in terms of monthly mean of daily broadband horizontal values, $G_{d m}(0)$. Then, the PV yield assessment requires obtaining the hourly values as a previous step.

Available literature offers several models for each of these steps, what leads to a huge amount of possible combinations. The objective of this paper is to assess the performance of some of the most used models pointing out the best-performing combinations. The whole conversion process is considered, where each model is evaluated in terms of uncertainty and impact on the final production estimations. 31 models have been selected according to previous reviews and to the IES-UPM experience [8-27].

Accuracy is assessed by comparing the modelling predictions with the experimental values recorded at 19 commercial PV plants at the Mediterranean belt, where pyranometers and reference PV modules are available for measuring $G(0)$ and $G^{e f}$, respectively. This work is restricted to silicon PV modules, which represents more than $90 \%$ of current commercial installations [28].

Finally, looking for a clearer presentation, from now on we will refer only to horizontal and in-plane (thus, avoiding the terms broadband and effective) irradiation. Table 1 summarizes the irradiation nomenclature used.

\section{Modelling from hourly values}

Fig. 1 shows the modelling path when starting from horizontal hourly irradiation. This is the case, for example, when the Typical Meteorological Year (TMY) is available. Each box represents a modelling step and includes the corresponding output values. Following a widely-extended practice, for calculation purposes, hourly irradiations $\left(\mathrm{Wh} / \mathrm{m}^{2}\right)$ are assimilated to irradiance values $\left(\mathrm{W} / \mathrm{m}^{2}\right)$ at the centre of the corresponding hour. Symbols $G, B, D$ and $A L$ represent, respectively, global, direct, diffuse and albedo components.

\subsection{Decomposition models}

Decomposition models allow the global radiation to be separated into its direct and diffuse components through the diffuse fraction index, $k_{d}=D(0) / G(0)$, by means of empirical correlations of the latter with the clearness index, $k_{t}$. Table 2 summarizes the equations 
Table 1

Irradiation nomenclature.

\begin{tabular}{ll}
\hline Symbol & Irradiation concept \\
\hline$G(0)$ & Hourly broadband horizontal \\
$G_{d}(0)$ & Daily broadband horizontal \\
$G_{d m}(0)$ & Monthly mean of daily broadband horizontal \\
$G^{e f}$ & Hourly effective in-plane \\
$G_{d}^{e f}$ & Daily effective in-plane \\
$G_{y}^{e f}$ & Yearly effective in-plane \\
$G_{E}^{e f}$ & Experimental hourly effective in-plane \\
$G_{S}^{e f}$ & Simulated hourly effective in-plane \\
$G_{m}(0)$ & Hourly broadband horizontal irradiation for the mean day of the \\
& month \\
\hline
\end{tabular}

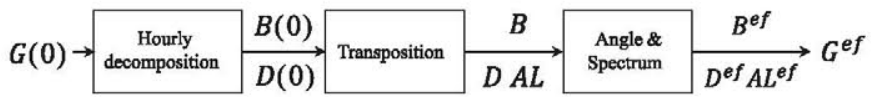

Fig. 1. Modelling process for obtaining the effective in-plane hourly irradiation when starting from broadband horizontal hourly data.

describing each of the seven models selected in this work and introduces the corresponding nomenclature. It includes the linear equation proposed by Orgill-Holland [29] as well as two polynomial equations defined by Erbs [30] and de Miguel [31], the latter being proposed specifically for the Mediterranean region. Reindl [32] and Skartveit [33] incorporate the solar elevation angle, $\alpha_{S}$, as independent variable. A further proposal by Skartveit [34] adds an hour-to-hour variability index, $\sigma_{3}$. Finally, the $B R L$ logistic model proposed by Ridley [35], includes a persistence parameter, $\phi$, the daily clearness index, $K_{t}$, and the apparent solar time, $A_{S}$, as predictors. It is worth mentioning that a recently published extensive review of 140 decomposition models concluded that: "Compared to the very first decomposition model that was introduced some 55 years ago, most of more recent models do not generally offer much improved accuracy, except maybe locally for the area for which they were designed" [12]. This sentence suggests that our model selection is as good as any other possibility.

\subsection{Transposition models}

The irradiance components on an arbitrarily oriented surface are given by:

$B=B(0) r_{B}$

$D=D(0) r_{D}$

$A L=G(0) r_{A L}$

The beam transposition factor is calculated straightforward from simple geometric considerations:

$r_{B}=\frac{\cos \theta_{i}}{\cos \theta_{Z}}$

where $\theta_{i}$ is the angle of incidence of the Sun's rays and $\theta_{Z}$ is the zenithal angle of the Sun, complementary of the elevation angle. Assuming isotropic albedo radiation, the corresponding transposition factor is also immediately deduced:

$r_{A L}=\rho \frac{1-\cos \beta_{\mathrm{S}}}{2}$

where $\beta_{\mathrm{S}}$ is the tilted surface angle and $\rho$ the ground reflection. In fact, the albedo radiation is scarcely relevant and rarely measured. Following a widely-extended practice, a general reflection value of 0.2 has been used in all the calculations.

The diffuse transposition factor depends on the assumption made for the sky radiance distribution. Table 3 presents the 8 modelling
Table 2

Horizontal hourly irradiation decomposition models.

\begin{tabular}{|c|c|}
\hline Model & Equation \\
\hline$O-H[29]$ & $k_{d}=\left\{\begin{array}{lr}1-0.249 k_{t} & k_{t}<0.35 \\
1.577-1.84 k_{t} 0.35 \leq & k_{t} \leq 0.75 \\
0.177 & k_{t}>0.75\end{array}\right.$ \\
\hline Erh [30] & $k_{d}=\left\{\begin{array}{lr}1-0.09 k_{t} & k_{t} \leq 0.22 \\
0.9511-0.1604 k_{t}+ & 4.388 k_{t}^{2}-16.638 k_{t}^{3} \\
+12.336 k_{t}^{4} & 0.22>k_{t} \leq 0.88 \\
0.177 & k_{t}>0.88\end{array}\right.$ \\
\hline$d M h[31]$ & $k_{d}=\left\{\begin{array}{lr}0.995-0.081 k_{t} & k_{t} \leq 0.21 \\
0.724+2.738 k_{t}-8.32 k_{t}^{2}+4.967 k_{t}^{3} 0.21< & k_{t} \leq 0.76 \\
0.177 & k_{t}>0.76\end{array}\right.$ \\
\hline $\operatorname{Reh}[32]$ & $k_{d}=\left\{\begin{array}{lr}1.02-0.254 k_{t}+0.0123 \sin \alpha_{S} & k_{t} \leq 0.3 \\
1.4-1.749 k_{t}+0.177 \sin \alpha_{S} & 0.3<k_{t}<0.78 \\
0486 k_{t}-0.182 \sin \alpha_{S} & k_{l} \geq 0.78\end{array}\right.$ \\
\hline$S-O[33]$ & $\begin{array}{l}k_{d}=\left\{\begin{array}{lr}1 & k_{t} \leq 0.2 \\
f\left(k_{t}\right)=1-\left(1-d_{1}\right)\left[0.27 \sqrt{K}+0.73 K^{2}\right] 0.2 \leq k_{t} \leq 1.09 k_{1} \\
1-1.09 k_{1}\left(1-f\left(1.09 k_{1}\right)\right) / k_{t} & k_{t} \geq 1.09 k_{1}\end{array}\right. \\
\text { where } \\
K=0.5\left(1+\sin \left(\pi\left(\frac{k_{t}-0.2}{k_{1}-0.2}\right)-0.5\right)\right. \\
d_{1}=0.15+0.43 \exp \left(-0.06 \alpha_{S}\right) \\
k_{1}=0.87-0.56 \exp \left(-0.06 \alpha_{S}\right)\end{array}$ \\
\hline$B R L$ [35] & $\begin{array}{l}k_{d}=\frac{1}{1+\exp \left(-5.32+7.28 k_{t}-0.03 A_{S}-0.0047 \alpha_{S}+1.72 K_{t}+1.08 \phi\right)} \\
\text { where } \\
\phi= \begin{cases}k_{t_{i+1}} & i=\text { sunrise } \\
\frac{k_{t_{i-1}}+k_{t_{i+1}} \text { sunrise }<}{2} i<\text { sunset } \\
k_{t_{i-1}} & i=\text { sunset }\end{cases} \end{array}$ \\
\hline Skh [34] & 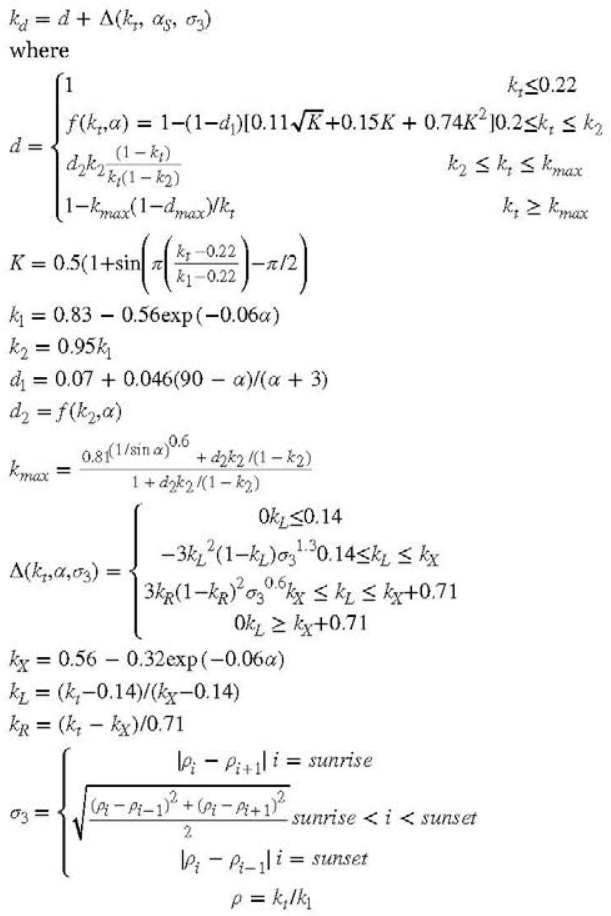 \\
\hline
\end{tabular}

possibilities selected. Liu and Jordan considered an isotropic sky [36]. Bugler [37], Hay [38] and Klucher [39] combined an isotropic and a circumsolar components using different weighting coefficients. Pérez 
Table 3

Horizontal to in-plane irradiance transposition models.

\begin{tabular}{|c|c|}
\hline Model & Equation \\
\hline$L-J[36]$ & $r_{D}=\frac{1+\cos \beta_{S}}{2}$ \\
\hline Bug [37] & $r_{D}=\frac{1+\cos \beta_{S}}{2}+0.05 \frac{B(I)}{D(0)}\left(\cos \theta_{i}+\frac{1}{\cos \theta_{Z}}\left(\frac{1+\cos \beta_{S}}{2}\right)\right)$ \\
\hline Hay [38] & $\begin{array}{l}r_{D}=k_{H A Y} r_{B}+\left(1-k_{H A Y}\right) \frac{1+\cos \beta_{S}}{2} \\
\text { where } \\
k_{H A Y}=B(0) / B_{0}\end{array}$ \\
\hline Klu [39] & $\begin{array}{l}r_{D}=\frac{1+\cos \beta_{S}}{2}\left(1+f_{K} \cos ^{2} \theta_{i} \cos ^{3} \theta_{Z}\right)\left(1+f_{K} \sin ^{3}\left(\frac{\beta_{S}}{2}\right)\right) \\
\text { where } \\
f_{K}=1-\left(\frac{D(0)}{G(0)}\right)^{2}\end{array}$ \\
\hline $\operatorname{Per}[40]$ & $\begin{array}{l}r_{D}=k_{1} r_{B}+\left(1-k_{1}\right) \frac{1+\cos \beta_{S}}{2}+k_{2} \sin \beta_{S} \\
\text { where } k_{1} \text { and } k_{2} \text { are determined by the Perez coefficients }\end{array}$ \\
\hline $\operatorname{Ret}[41]$ & $r_{D}=k_{H A Y} r_{B}+\left(1-k_{H A Y}\right) \frac{1+\cos \rho_{S}}{2}\left(1+\sqrt{\frac{B(0)}{G(0)}} \sin ^{3}\left(\frac{\beta_{S}}{2}\right)\right)$ \\
\hline Skt [42] & $\begin{array}{l}r_{D}=k_{H A Y} r_{B}+\left(1-k_{H A Y}-Z\right) \frac{1+\cos \hat{\beta}_{S}}{2}+Z \cos \beta_{S} \\
\text { where } \\
Z=\max \left(0.3-2 k_{H A Y}, 0\right)\end{array}$ \\
\hline \multirow[t]{4}{*}{ Gue [43] } & $\begin{array}{l}r_{D}=\left(1-N_{g}\right) R_{d 0}+N_{g} R_{d 1} \\
\text { where } \\
N_{g}=\max (\min (Y, 1), 0)\end{array}$ \\
\hline & $\begin{array}{l}R_{d 0}=\exp \left(a_{0}+a_{1} \cos \theta_{i}+a_{2} \cos ^{2} \theta_{i}+a_{3} \cos ^{2} \theta_{i}\right)+F\left(\beta_{S}\right) G\left(\alpha_{S}\right) \\
R_{d 1}=\frac{1+\cos \beta_{S}}{2}-\frac{\frac{1}{\pi}\left(\beta_{S} \cos \beta_{S}-\sin \beta_{S}\right)+\frac{1-\cos \beta_{S}}{2}}{1+\frac{3}{2 b}}\end{array}$ \\
\hline & $Y=\left\{\begin{array}{c}6.6667 \frac{D(0)}{G(0)}-1.4167 i f \frac{D(0)}{G(0)} \leq 0.227 \\
1.2121 \frac{D(0)}{G(0)}-0.1758 \text { otherwise }\end{array}\right.$ \\
\hline & $\begin{array}{l}F(\beta)=\frac{1-0.2249 \sin ^{2} \beta_{S}+0.1231 \sin 2 \beta_{S}-0.0342 \sin 4 \beta_{S}}{0.7751} \\
\text { and } G\left(\alpha_{S}\right), a_{0}, a_{1}, a_{2}, a_{3} \text { are coefficients function of } \alpha_{S}\end{array}$ \\
\hline
\end{tabular}

Table 4

Angular and spectral correction models applied to the in-plane irradiation.

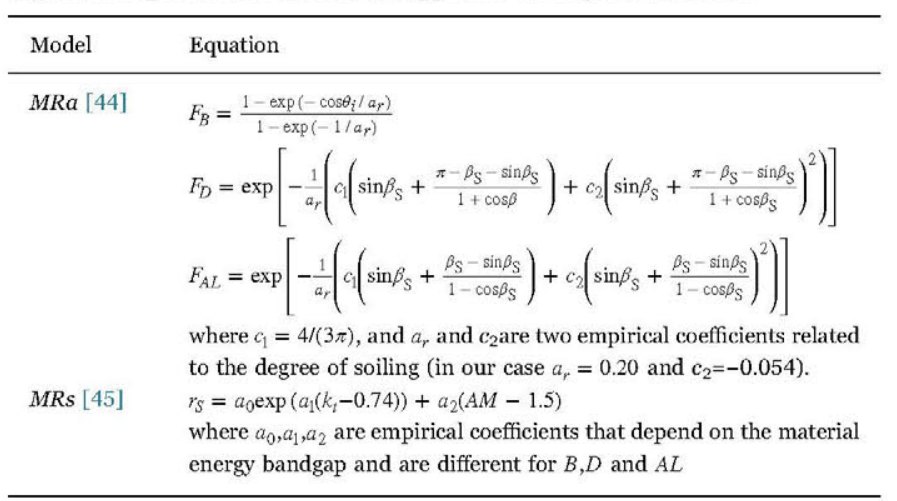

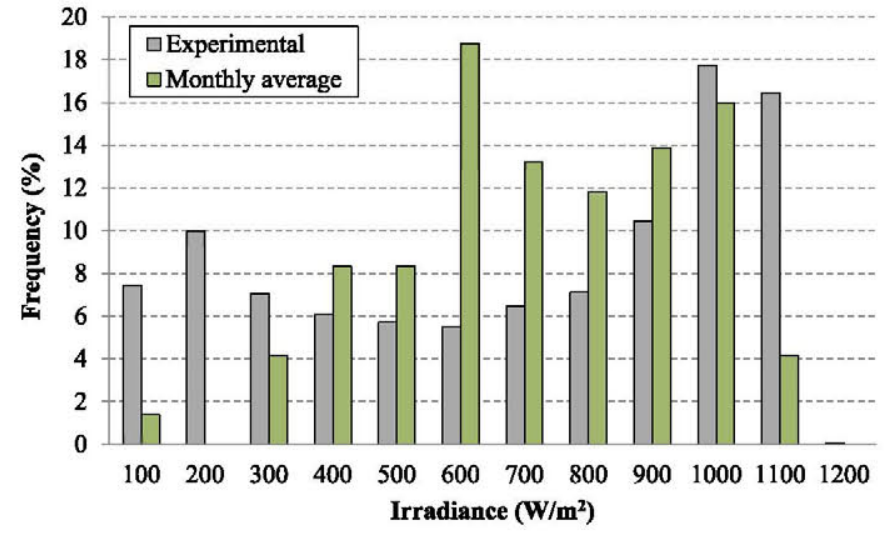

Fig. 3. Frequency distribution of the experimental and simulated (monthly average profile), hourly irradiations in a double-axis tracking system. The simulated profile overestimates (underestimates) the weight of medium (extreme) values.

[40] and Reindl [41] added a horizon brightening component and Skartveit [42], in addition, compensated for the radiation around the zenith in overcast skies. Finally, Gueymard constructed a weighted sum of clear and overcast sky irradiations [43].

\subsection{Angular and spectral corrections}

Due to different shape and tilt, some dust effect differences can arise between pyranometers and reference PV modules. Moreover, dust affection can vary throughout the year according to the location characteristics (climate, rainfall, surroundings, etc.). In the absence of measurements concerning soiling evolution, we have postulated for all the PV plants a constant soiling reducing the transmittance at normal incidence by $2 \%$. Then, the angular transmittance of reference PV modules has been assessed by means of the Martin-Ruiz model [44]. This proposal formulates an equation for the ratio between the transmittance at a given incident angle, $\theta_{i}$, and the transmittance at normal incidence. This equation, $F_{\mathrm{B}}$, is directly applied to the direct and circumsolar irradiance components, and allows corresponding equations to be derived for the diffuse and albedo components, $F_{\mathrm{D}}$ and $F_{\mathrm{AL}}$, respectively, as a function of the tilt surface angle, $\beta_{\mathrm{S}}$. An advantage of this model is that internal coefficients can be adjusted to the amount of dirt. Table 4 sets out the corresponding formulae.

On the other hand, we have also analysed whether the inclusion of a spectral model improved the simulation results or not. In particular, we have considered the one proposed by Martin and Ruiz [45], which characterizes the Earth's atmosphere by means of $k_{t}$ and $A M$ (Air Mass) and defines a spectral correction factor, $r_{S}$, for each irradiance component. The corresponding equation is also presented in Table 4. The final effective irradiance, $G^{\text {ef }}$, is given by adding the three corrected components:

$G^{e f}=B F_{B} r_{s B}+D F_{D} r_{s D}+A L F_{A L} r_{s A L}$

\section{Modelling from the monthly average of daily irradiation}

\subsection{With monthly average of daily irradiance profiles}

Most widely available solar radiation databases [46,47] usually provide information in terms of long term monthly averages of daily

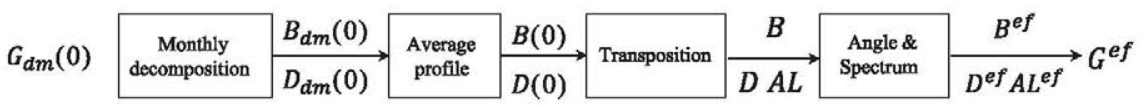

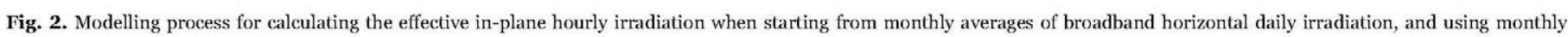
average daily irradiance profiles. 


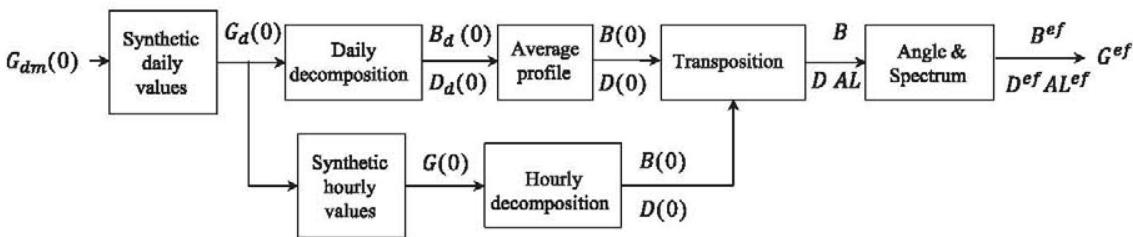

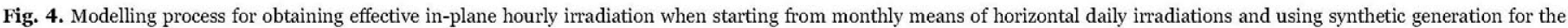
corresponding values of each day of the month.

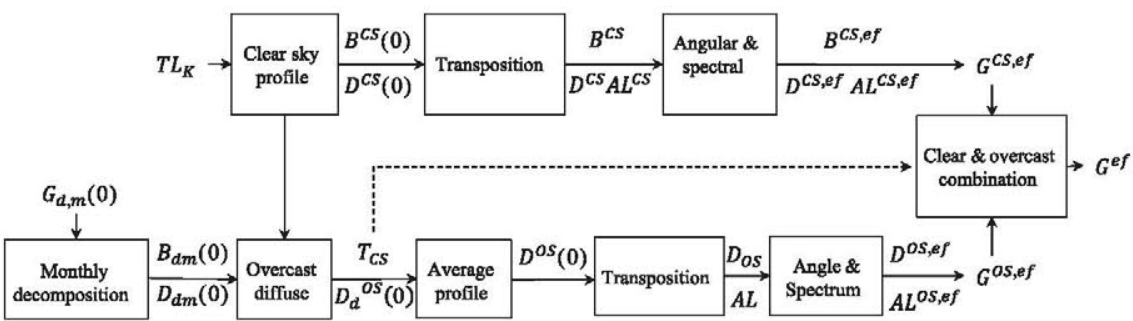

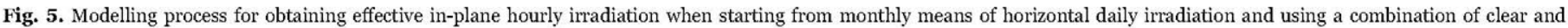
overcast sky days.

Table 5

Daily irradiance profile model.

\begin{tabular}{ll}
\hline Model & Equation \\
\hline Ms $[48]$ & $G(0)=r_{G} G_{d, m}(0)$ \\
& $D(0)=r_{D} D_{d, m}(0)$ \\
& $B(0)=G(0)-D(0)$ \\
& where \\
& $D_{d, m}(0)=G_{d, m}(0) \kappa_{d}$ \\
& $r_{D}^{\prime}=\frac{\pi}{24} \times \frac{\cos \omega-\cos \omega_{S}}{\omega_{S} \cos \omega_{S}-\sin \omega_{S}}$ \\
& $r_{G}^{\prime}=r_{D}(a+b \cos \omega)$ \\
& $a=0.409-0.5016 \sin \omega_{S}+\pi / 3$ \\
& $b=0.6609+0.4767 \sin \omega_{S}+\pi / 3$ \\
& $\omega_{S}$ is the azimuthal solar sunrise angle and $\omega$ is the azimuthal solar \\
& angle.
\end{tabular}

horizontal irradiation, $G_{d m}(0)$. Subscripts " $d$ " and " $m$ " mean the daily and monthly average of daily values, respectively. Figs. 2, 4 and 5 show three different modelling paths for deriving the corresponding irradiance values, $G(0)$, from this information. Then, the modelling continues as explained in the previous section.

Following the publication chronological order, the first approach (Fig. 2) consists of defining the irradiance daily profile in terms of irradiance divided by daily irradiation and on assuming that the profile of the extraterrestrial horizontal solar radiation, which is derived from simple geometrical considerations, translates directly into the profile of the diffuse component, while a slight empirical correction is needed for the global radiation [48]. This allows global and diffuse irradiance values to be obtained as the average day of each month, $G_{m}(0)$ and $D_{m}(0)$. Corresponding equations are given in Table 5 . Note that subscript " $\mathrm{m}$ " means, again, monthly averaging and preserves the significance of irradiance.

The diffuse component of the average daily irradiation, $D_{d m}(0)$, is derived from a decomposition model consisting, again, of an empirical relationship between the clearness index and the diffuse fraction, but this time specifically adapted to the monthly average of daily values. Table 6 presents the four selected alternatives for the decomposition process: the linear relationship proposed by Page [49], as well as two polynomial equations defined by Collares [48] and Erbs [30] and a local correlation proposed for Madrid by Macagnan [50]. It is worth

Table 6

Decomposition models for monthly average of horizontal daily irradiations.

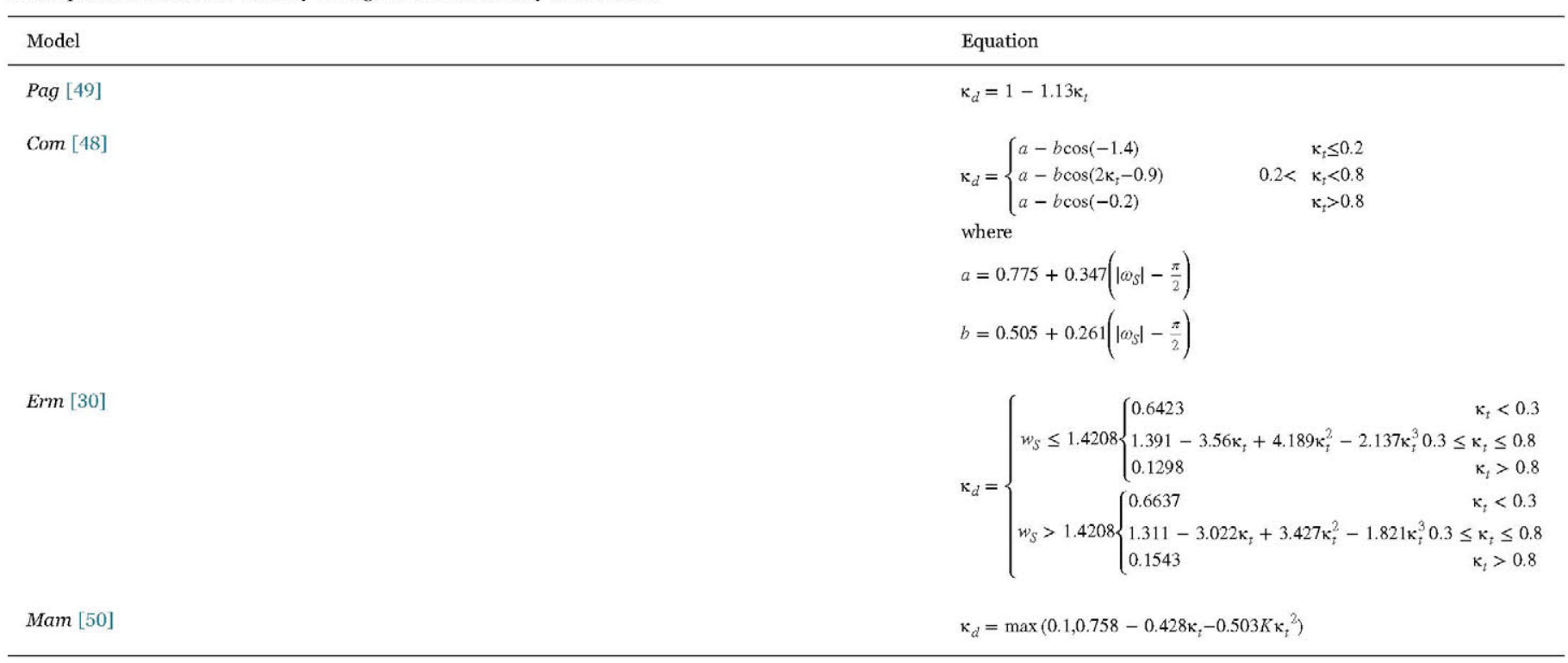


Table 7

Horizontal daily irradiation decomposition models.

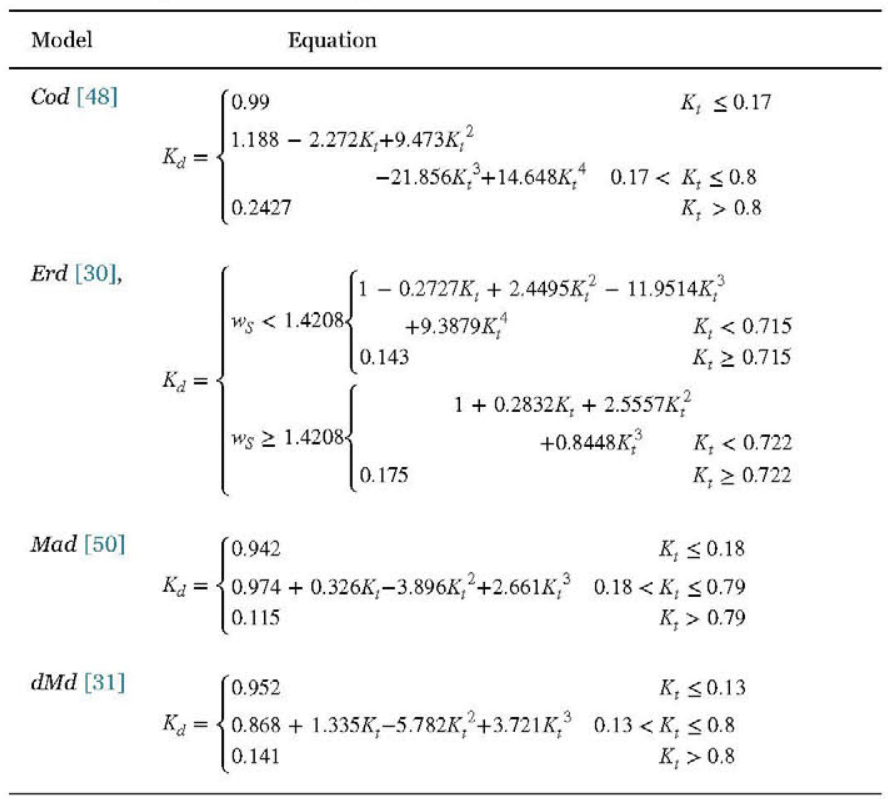

Table 8

Modelling options for combining clear and overcast sky days.

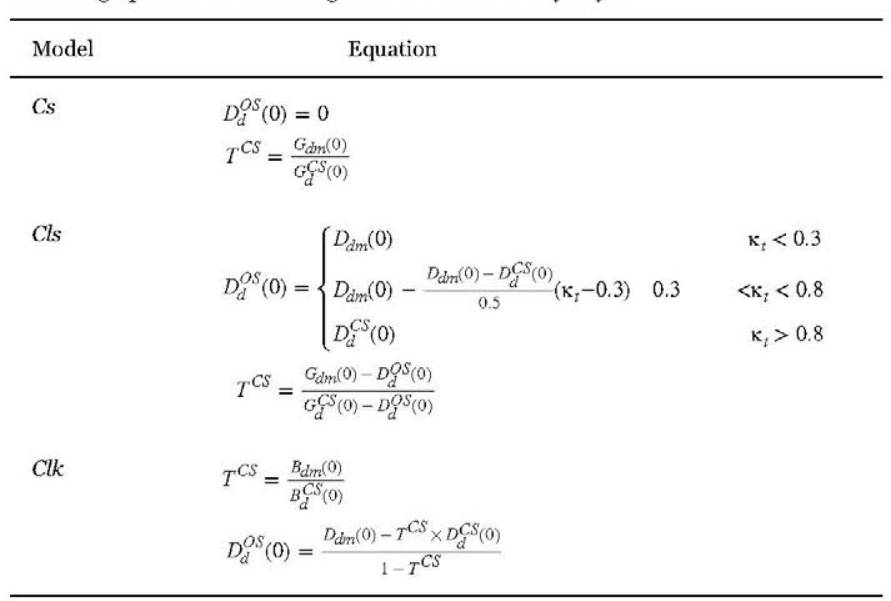

mentioning that some solar radiation databases also provide $D_{d m}(0)$ data (NASA, PVGIS), obviously avoiding the need of this decomposition step. Whatever the case, this approach requires only 12 days to be dealt with and is rather simple to implement but, because of the monthly averaging, the weight of the medium values at the corresponding irradiance frequency distribution tends to be larger than the one observed. Fig. 3 shows a representative example of high irradiances being more frequent than what derived from the mean profile. Note that as the relationship between PV output power and irradiance is affected by non-linear effects, this frequency distribution affects the PV yearly yield estimation (in some cases, up to $2-3 \%$ differences are observed).

\subsection{With synthetic generation of daily irradiation data}

This problem can be overcome by the synthetic generation of series of daily irradiation values (Fig. 4) by the method proposed by AguiarCollares [51]. This way, a different irradiation value, $G_{d}(0)$, is available for each day of the month. Then, a decomposition model, adapted to individual daily values, allows the diffuse component, $D_{d}(0)$, to be derived. Table 7 presents the four alternatives selected for such decomposition model: two general polynomial relations, proposed by Collares [48] and Erbs [30], the latter depending also on the sunrise angle, $w_{S}$, and two local correlations, proposed by Macagnan [50] and de Miguel [31], for Madrid and for the Mediterranean belt, respectively. Then, the aforementioned procedure for deriving irradiance profiles can be applied, leading to $G(0)$ and $D(0)$ values for each day. A possible refinement consists of the direct generation of synthetic irradiance values, also following an Aguiar-Collares proposition [52]. This way, a series of $G(0)$ is obtained. It is worth noting that this modelling path requires dealing with 365 days of data.

\subsection{With combinations of clear and overcast sky days}

Finally, recognizing that real skies can be understood as a succession of clear and cloudy moments, irradiance values for a particular day can also be derived from combining the irradiance profiles of a completely clear sky and of a completely overcast sky, whose combined irradiation coincides with the corresponding input data for the day concerned, $G_{d m}(0)$ (Fig. 5). Following the proposal of the European Solar Radiation Atlas (ESRA) for modelling the direct and diffuse irradiance components of the clear sky, $B^{C S}(0)$ and $D^{C S}(0)$ have been obtained, using the Linke coefficients for the atmosphere turbidity as input data [53]. Subsequent integrals give the corresponding daily irradiation values, $B_{d}^{C S}(0)$ and $D_{d}^{C S}(0)$, respectively. Note that defining $T^{C S}$ as the fraction of the day with clear sky leads to:

$T^{C S} \times\left[B_{d}^{C S}(0)+D_{d}^{C S}(0)\right]+\left(1-T^{C S}\right) \times D_{d}^{O S}(0)=G_{d m}(0)$

where $D_{d}^{O S}(0)$ is the daily horizontal irradiation, all diffuse, of the overcast sky. Table 8 presents different assumptions for setting the mutually dependent variables $T^{C S}$ and $D_{d}^{O S}(0)$. The simplest one is neglecting the overcast day component, setting $D_{d}^{O S}(0)=0$. A more sensible approach is to realize that the possible minimum and maximum values of $D_{d}^{O S}(0)$ are $D_{d}^{C S}(0)$ and $D_{d m}(0)$, respectively, and to derive the former as a combination of these two values. We have postulated a particular equation for this purpose, using $\kappa_{t}$ as weighting factor. Another appealing possibility is setting $T^{C S}=B_{d m}(0) / B_{d}^{C S}(0)$. Note that the components of the daily horizontal irradiation, $D_{d m}(0)$ and $B_{d m}(0)$, are easily deduced from any of the decomposition models listed in Table 6 . Whatever the case, this modelling path requires dealing with 24 days, 2 by month, whose results are combined to get the final value. For example, the final monthly mean daily effective irradiation, $G_{d m}^{e f}$, is obtained as:

$G_{d m}^{e f}=G_{d m}^{C S, e f} \times T^{C S}+G_{d m}^{O S, e f} \times\left(1-T^{C S}\right)$

\section{Experimental database}

The experimental bases of this work are the broadband horizontal and the effective in-plane irradiances, respectively recorded from Bclass pyranometers and reference PV modules at 19 commercial PV plants located in the Mediterranean region (Spain, Portugal and Italy). These installations include static and double-axis tracking systems. Fig. 6 shows their location and type. All of them are in a relatively narrow latitude range and in a temperate climate region. Therefore, the results of this study are somewhat restricted to sites with these characteristics. Both, pyranometers and reference PV modules are submitted to routine maintenance procedures on large PV plants, which typically include a cleaning campaign per year, and are recalibrated biannually. Starting from the original ten-minute records, one year of hourly irradiation data was available in four installations, two years in other thirteen and three years in two more locations. As this data was not specifically recorded for research purposes, it entails a higher uncertainty. According to the calibration certificates of the pyranometers and the reference modules involved, a $3 \%$ uncertainty 


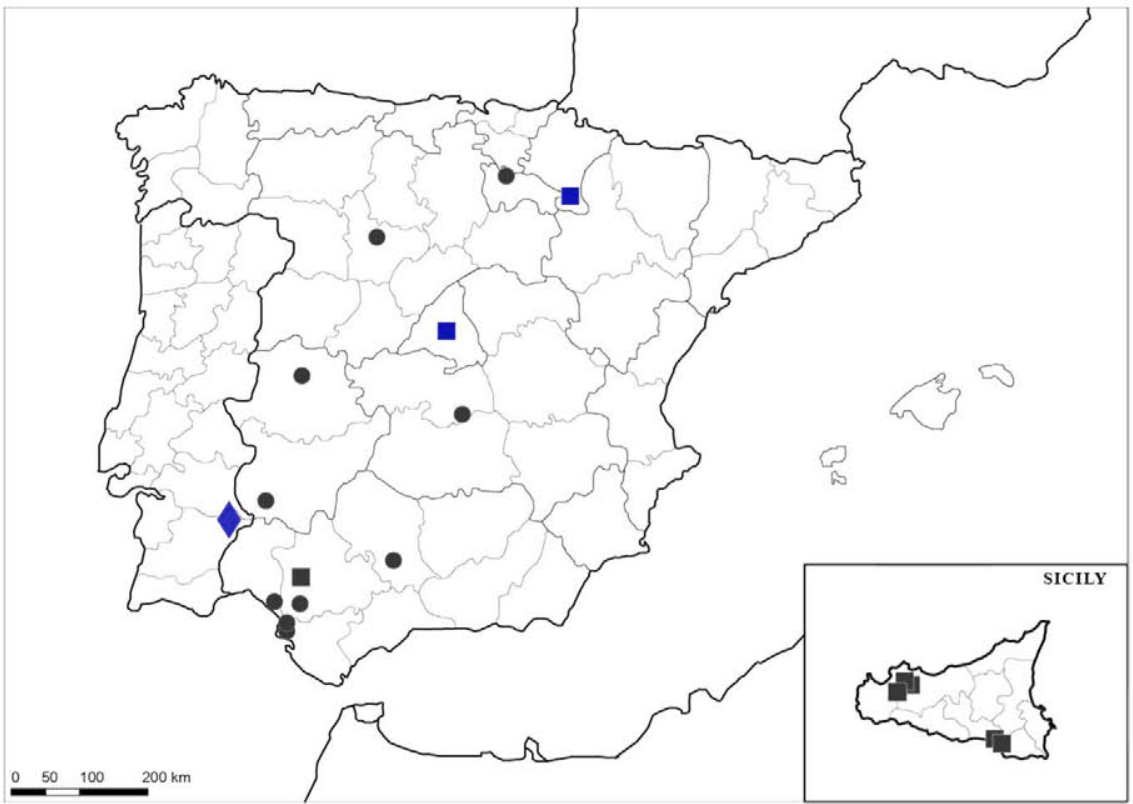

Fig. 6. Geographic distribution of the PV plants providing experimental data for this work. Squares represent static structures and diamonds and circles represent single and doubleaxis tracking configuration, respectively. Black and blue figures stand, respectively, for testing and control populations.

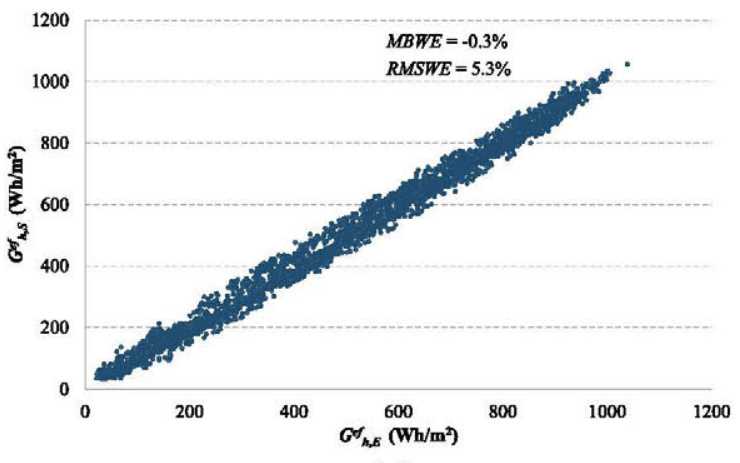

(a)

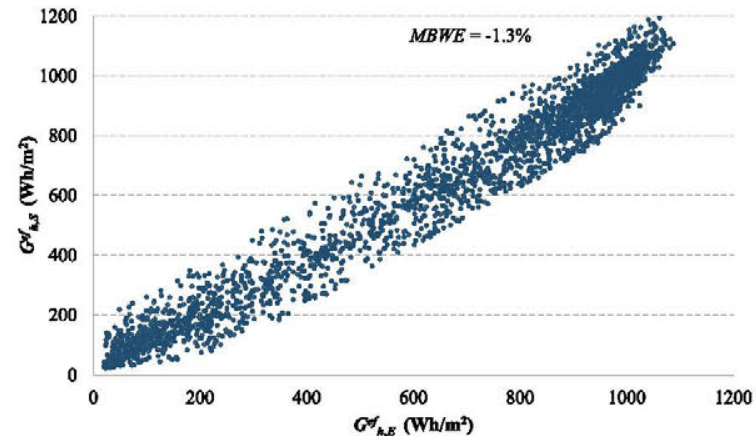

(b)

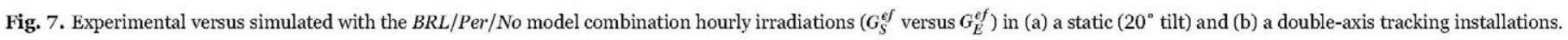

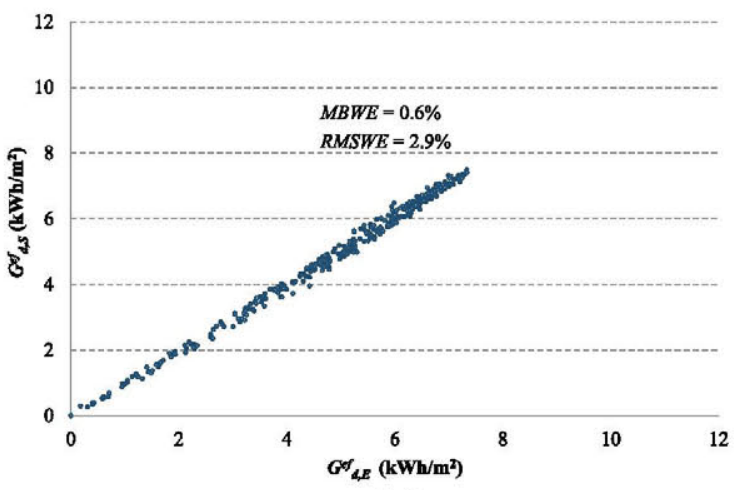

(a)

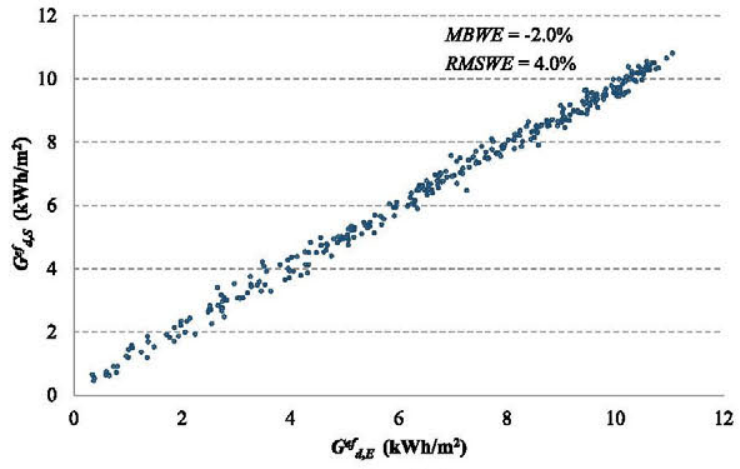

(b)

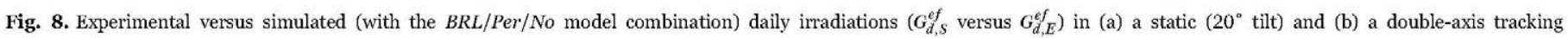
installations.

can be considered, which is coherent with the state of art of the operation surveillance in PV plants. Before model evaluation, a data filtering was carried out following the recommendations of Polo et al. in order to reduce the effect of possible defective records [54]. Hence, 25 year-plant data were finally available.

\section{Model evaluation}

The underlying exercise consists of comparing experimental and simulated effective irradiation values. Simulations are carried out for each PV plant, year and model combination. This leads to 2800 
Table 9

Resulting metrics, expressed in\%, of the model combination $B R L / P e r / N o$ at hourly and daily levels, for a static and a double-axis tracking structures.

\begin{tabular}{|c|c|c|c|c|c|c|c|c|}
\hline \multirow[t]{2}{*}{ Metric (\%) } & \multicolumn{4}{|l|}{ Static } & \multicolumn{4}{|c|}{ Double-axis tracking } \\
\hline & Hourly & Daily & Monthly & Yearly & Hourly & Daily & Monthly & Yearly \\
\hline$M W E$ & -0.3 & 0.6 & 0.2 & 0.2 & -1.3 & -2.0 & -2.2 & -1.0 \\
\hline RMSWE & 5.3 & 2.9 & 1.8 & N.A & 8.9 & 4.0 & 3.5 & N.A \\
\hline KSWI & \multicolumn{4}{|c|}{13.7} & \multicolumn{4}{|c|}{61.6} \\
\hline
\end{tabular}

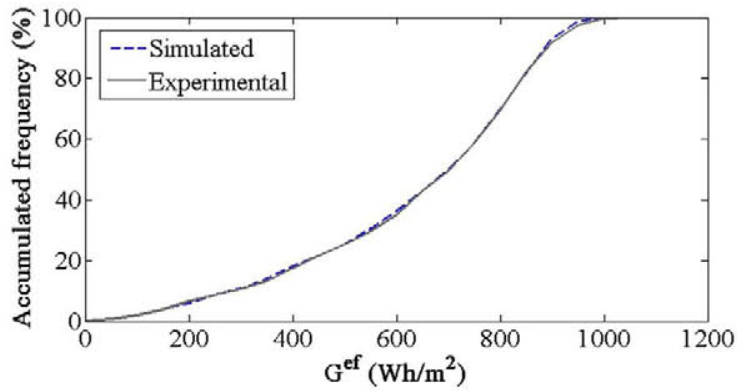

(a)

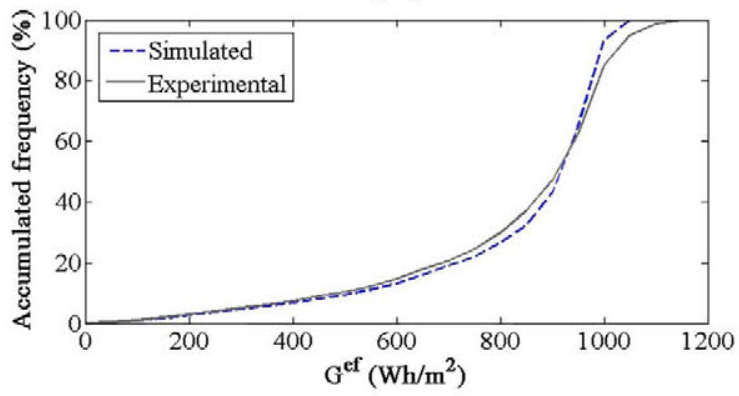

(c)

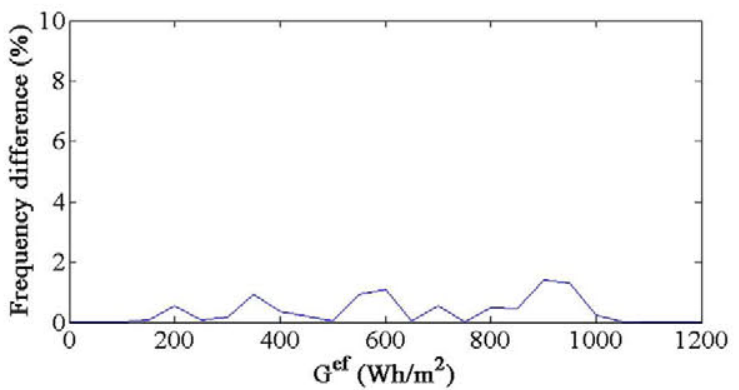

(b)

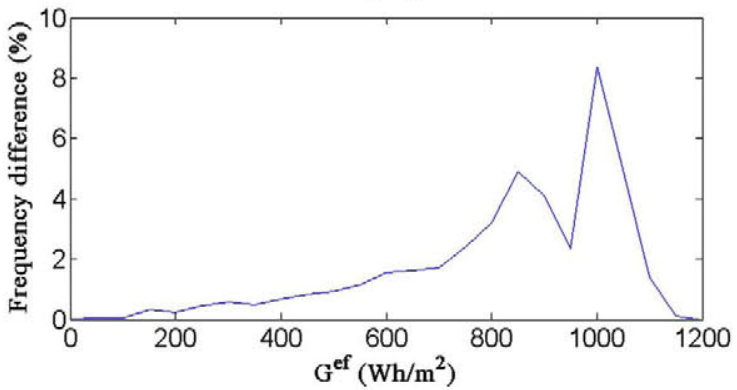

(d)

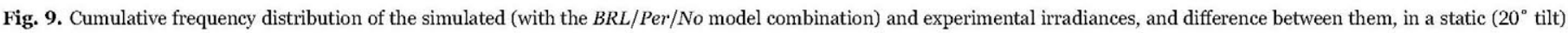
and a double-axis tracking installations.

different simulations when using hourly values as input and 10,800 when using monthly averages. These results are compared both in hourly and yearly terms. Attending to the difference between experimental and simulated values, model combinations are graded based on three different evaluation metrics:

- Fitting to the experimental measurements, calculated through the relative Mean Weighted Bias Error (MBWE), according to:

$M B W E=\frac{1}{n} \sum_{i} \frac{\left(G_{S, i}^{e f}-G_{E, i}^{e f}\right) \times G_{E, i}^{e f}}{\overline{G_{E}^{e f}}}$

where subscripts " $\mathrm{S}$ " and " $\mathrm{E}$ " refer to simulated and experimental values, respectively, while $i$ stands for each of the $n$ considered data. Note that errors are weighted by the irradiation to give each value a relative importance in energy production terms. This way, an irradiation error closely translates into energy production error, which is the relevant parameter in PV yield forecasting.

- Spread around the fit, through the relative Root Mean Squared Weighted Error (RMSWE), according to:

RMSWE $=\frac{1}{n} \sqrt{\sum_{i}\left(\frac{\left(G_{E, i}^{e f}-G_{S, i}^{e f}\right) \times G_{E, i}^{e f}}{G_{E}^{e f}}\right)^{2}}$

- Frequency distribution similarity, obtained from the KolmogorovSmirnov test Integral, as proposed by Espinar et al. [55], and weighted by the experimental in-plane irradiance (KSWI), according to:

$$
K S W I=\frac{\sum_{j}\left(\left|f_{G_{E, j}^{e f}}-f_{G_{S, j}^{e f}}\right| \times G_{E, j}^{e f}\right)}{a_{\text {critical }} \times \overline{G_{E}^{e f}}}
$$

where $f_{G_{E}^{e f}, j}$ is the frequency occurrence of the $G_{E}^{e f}$ within a certain irradiance interval $j ; j \in 1, \ldots, m, m$ being the number of bins in the frequency distribution; $a_{\text {critical }}=1.63 / \sqrt{N} \times m$; and $N$ the population size. For model comparison purposes, it suffices to consider that the lower the KSWI is, the more similar the experimental and the simulated values are. In particular, values lower than $100 \%$ imply that the model passes the test and, therefore, that the simulated and experimental distributions are statistically equivalent.

After performing all the simulations and calculating the corresponding metrics, an ANOVA test is applied for each model combination. This allows several statistical distributions to be separated in accordance with their variance and is especially useful when trying to identify different combined sources of uncertainty [56] .

It is worth noting that, whatever the modelling path, the result of a simulation is a set of in-plane hourly irradiation values: 4380 when modelling from the $T M Y$ or generating a synthetic series of daily irradiation (Figs. 1 and 4), 288 when combining clear sky and overcast sky days (Fig. 5) and 144 when relying on average daily irradiance profiles (Fig. 2). Then, these hourly values can be integrated in different time periods: day, month and year. This way, experimental and 


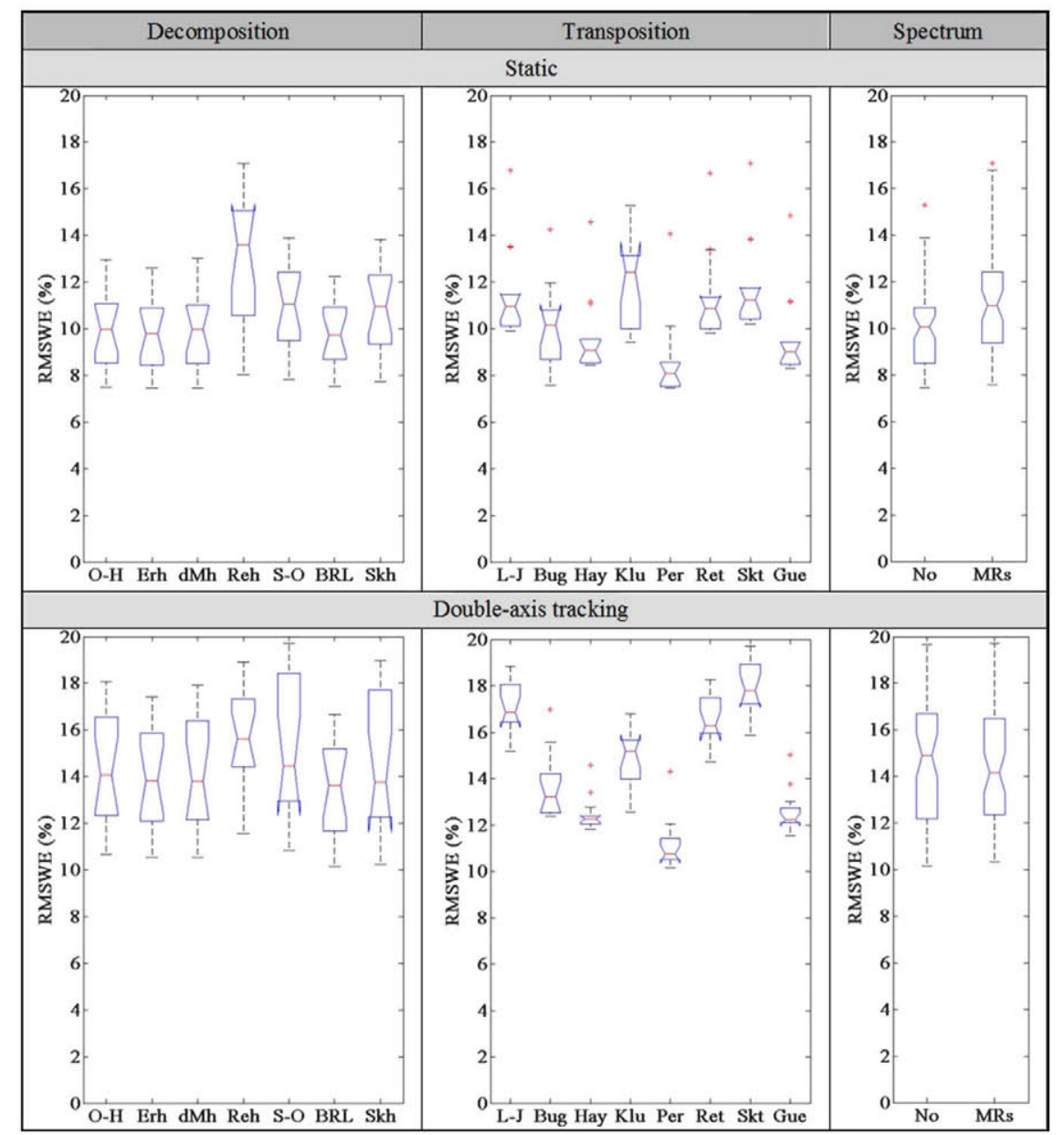

Fig. 10. ANOVA analysis applied to the RMSWE of the in-plane hourly irradiation results when using the corresponding horizontal values as input $\left(G_{S}^{e f}\right.$ versus $\left.G_{E}^{e f}\right)$ for each of the models considered and for static and tracking systems separately.

simulated values can also be compared at these different time spans. However, this presentation pays particular attention to the RMSWE of the yearly irradiation results, due to its key role in the evaluation of the financial attractiveness of a PV project [1].

Finally, the evaluation has been made, first, with 25 year-plant coming from 16 "testing" installations, and the robustness of the derived conclusions have been checked with a 4 year-plant dataset corresponding to the 3 "control" installations.

\section{Results}

\subsection{Modelling from hourly irradiation data}

Fig. 7 presents, as an example, $G_{S}^{e f}$ versus $G_{E}^{e f}$, simulated with the $B R L / P e r / N o$ model combination, for two locations representative of static and double-axis tracking, respectively. Both regression coefficients are close to one, within a $\pm 1.5 \%$ range. $\mathrm{A}$ higher dispersion is observed in the tracking case, in coherence with the larger deviation from the horizontal plane and with possible tracking misalignments. It can also be observed how, in the static case, hourly irradiations are more homogeneously distributed while, in the tracking case, there is a concentration of values at low and especially high irradiances.

Fig. 8 shows the same comparisons in terms of daily irradiations. As expected from the integration process, $M B W E$ values are almost the same (errors are weighted by irradiation), while $R M S W E$ values decrease due to mutual compensation. Table 9 presents the corresponding metrics results, also in monthly and yearly terms.

Fig. 9 shows, for the same installations and model combination, the cumulative weighted frequency distribution of the hourly measured and simulated irradiances (Figs. 9-a and 9-c). It also presents the weighted frequency differences (Figs. 9-b and 9-d). The resulting KSWI values are $13.7 \%$ and $61.6 \%$, respectively.

\subsubsection{In-plane hourly irradiation}

Fig. 10 presents the results of an ANOVA exercise applied to the RMSWE of the hourly irradiation results for all the locations. It is worth remembering that each box shows the distribution of the RMSWE values corresponding to all the possible model combinations that include the model that name the box. For example, the first box in the upper left corner of the figure presents the distribution of the 600 RMSWE values corresponding to the 25 years of available data for the testing PV plants multiplied by the 24 model combinations ( 8 transposition $\times 3$ spectral) that use the $O-H$ model for the decomposition step. Fig. 11 presents the same exercise, but this time applied to the KSWI of the hourly irradiation results. For more details, Tables 2022 (Appendix 1) present the numerical values of the median resulting from the ANOVA exercise applied to each metric.

Once the models were individually evaluated, the best-performing combinations were assessed. Table 10 presents the resulting metrics of some particularly suitable and unsuitable sets. 


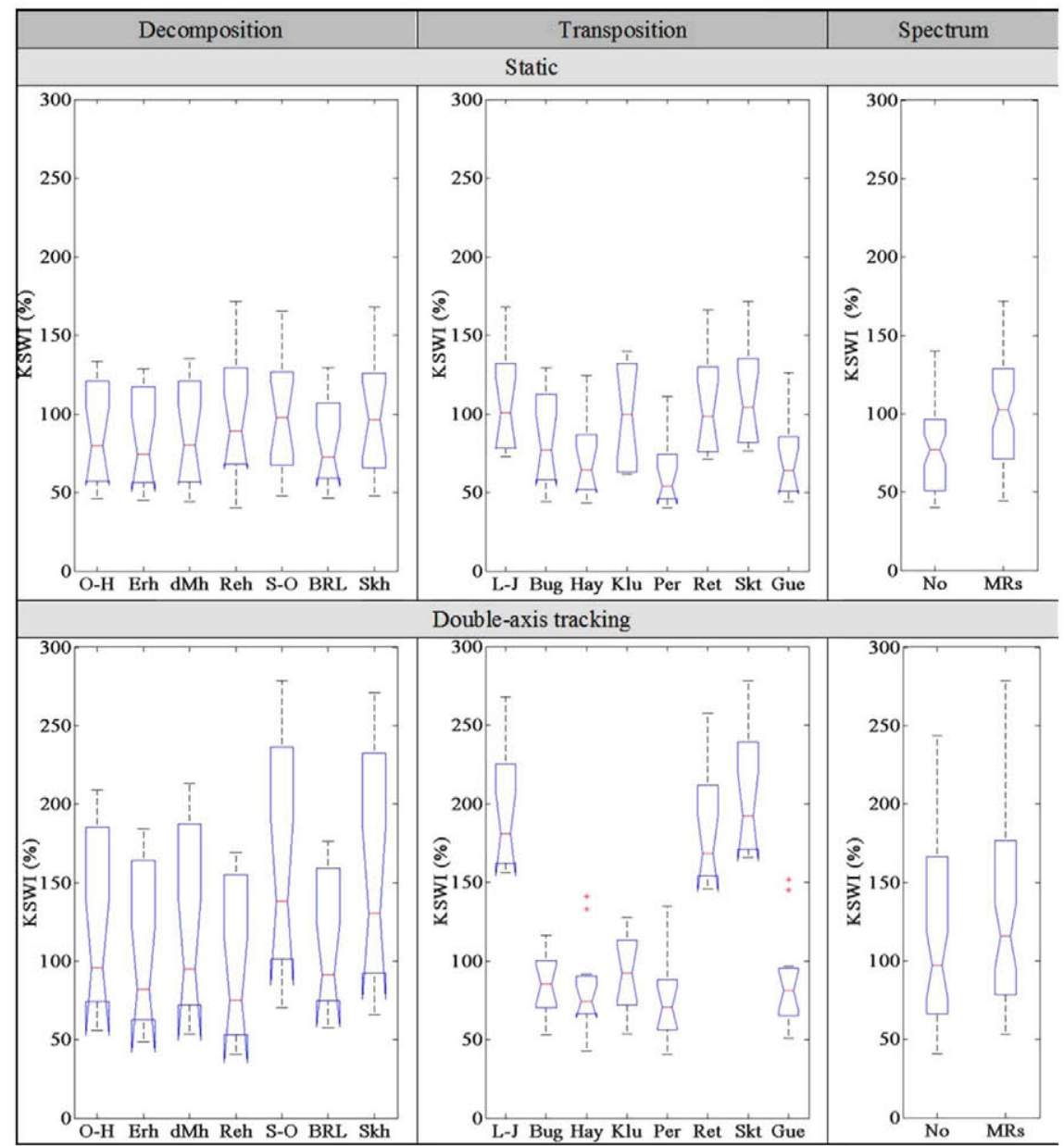

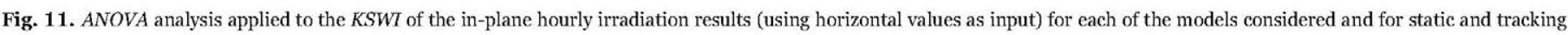
systems.

Table 10

Hourly metrics for some best and worst model combinations when starting from hourly horizontal irradiation.

\begin{tabular}{|c|c|c|c|c|c|c|}
\hline \multirow[t]{2}{*}{ Model combination } & \multicolumn{3}{|l|}{ Static } & \multicolumn{3}{|c|}{ Double-axis tracking } \\
\hline & MBWE (\%) & RMSWE (\%) & KSWT (\%) & MBWE (\%) & RMSWE (\%) & KSWI (\%) \\
\hline \multicolumn{7}{|c|}{ Best-performing combinations } \\
\hline BRL/Per/No & -1.4 & 7.5 & 46 & -1.4 & 10.2 & 58 \\
\hline$d M h / B u g / M R s$ & -1.1 & 7.6 & 44 & -3.4 & 12.4 & 66 \\
\hline $\mathrm{Reh} / \mathrm{Hay} / \mathrm{No}$ & -3.3 & 8.5 & 43 & -2.9 & 12.1 & 43 \\
\hline $\mathrm{O}-\mathrm{H} / \mathrm{Per} / \mathrm{No}$ & -1.6 & 7.5 & 46 & -2.6 & 10.7 & 56 \\
\hline \multicolumn{7}{|c|}{ Worst-performing combinations } \\
\hline$S k h / L-J / M R s$ & -9.9 & 13.4 & 159 & -15.9 & 18.3 & 258 \\
\hline S-O/Reh/MRs & -10.0 & 13.5 & 164 & -15.8 & 18.1 & 261 \\
\hline
\end{tabular}

The repetition of the ANOVA exercise in the control PV plants is summarized in Tables 26-28 in Appendix 1, and essentially confirmed the results obtained in the testing installations.

\subsubsection{In-plane yearly irradiation}

Fig. 12 shows, as an example, the comparison of the simulation, using the $B R L / P e r / N o$ combination, and the experimental yearly irradiations resulting from the integration of hourly values, and for all the installations. The overall results are $M W B E=-0.8 \%$ and RMSWE $=2.6 \%$.

Fig. 13 presents the results of the ANOVA exercise applied to the RMSWE of the yearly irradiation comparison for the testing PV plants. Results are presented in Tables 23-25 (Appendix 1). Again, the integration effect essentially maintains the $M B W E$ but significantly

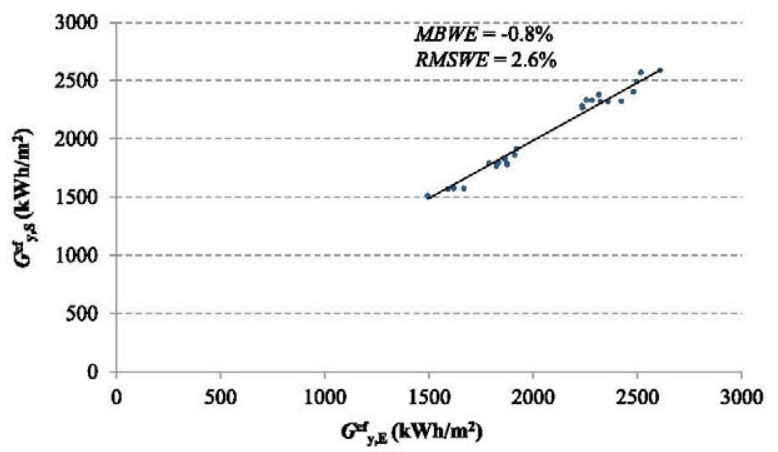

Fig. 12. Experimental versus simulated yearly in-plane irradiations for the 25 year-plant considered. 


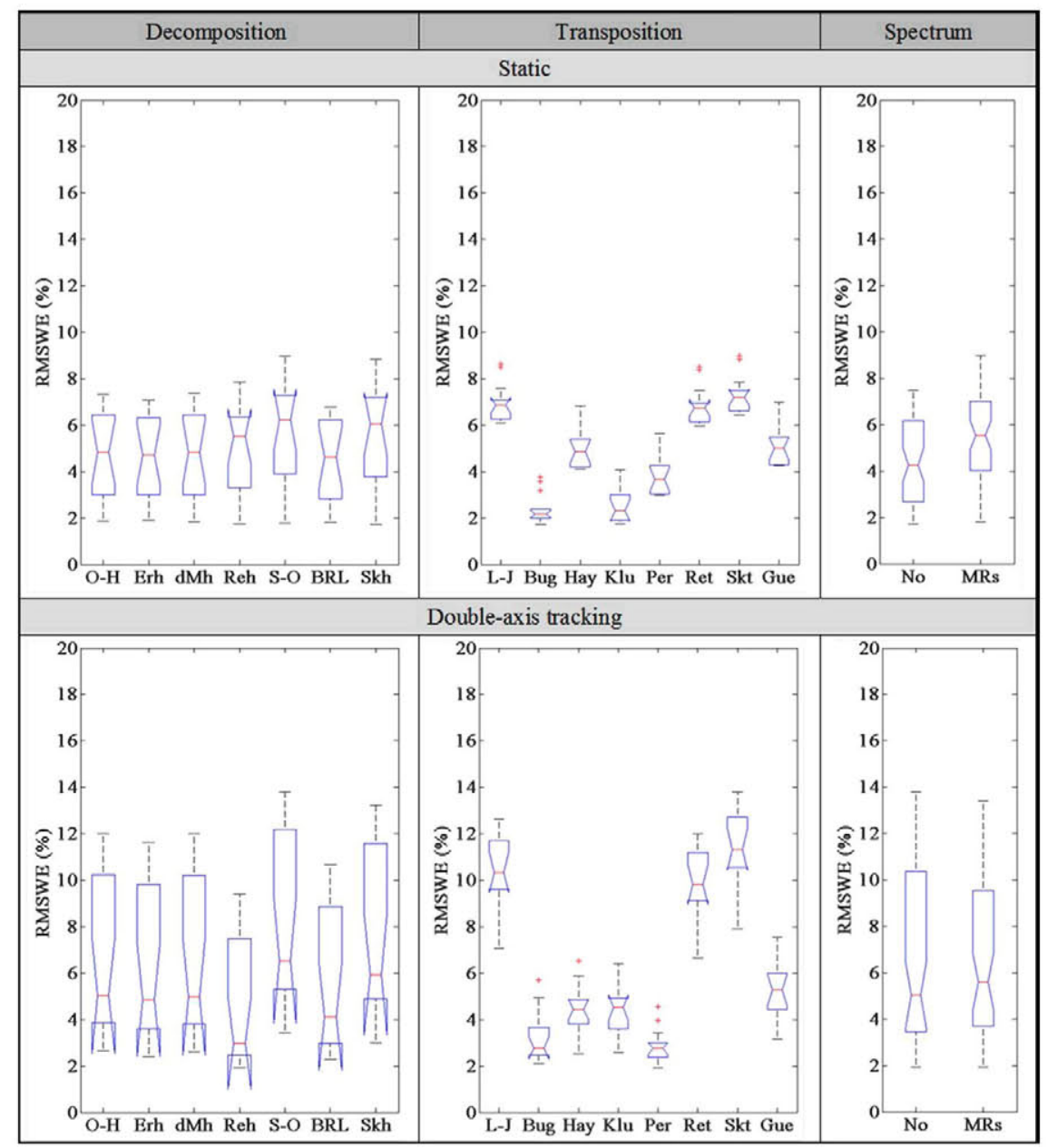

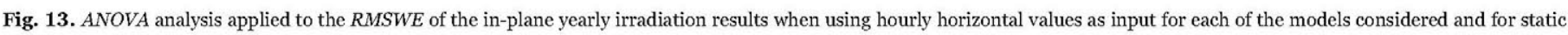
and tracking systems separately.

Table 11

Daily metrics of best and worst hourly model combinations when starting from hourly horizontal irradiation.

\begin{tabular}{llllll}
\hline Model combination & \multicolumn{2}{l}{ Static } & & & \multicolumn{2}{l}{ Double-axis tracking } \\
\cline { 2 - 3 } \cline { 5 - 6 } \cline { 5 - 6 } & MBWE & RMSWE & & MBWE & \multirow{2}{*}{ RMSWE } \\
\hline Best performing combinations & & & & \\
BRL/Per/No & -2.2 & 4.5 & & -1.9 & 5.8 \\
Erh/Bug/MRs & -1.3 & 3.9 & & -4.4 & 7.3 \\
dMh/Per/No & -3.8 & 5.7 & & -3.7 & 6.9 \\
Reh/Hay/No & -2.2 & 4.5 & & -3.5 & 6.6 \\
Worst performing combinations & & & & \\
Skh/L-J/MRs & -8.7 & 10.5 & & -16.2 & 16.9 \\
S-O/Reh/MRs & -8.8 & 10.6 & & -16.0 & 16.7 \\
\hline
\end{tabular}

reduces the RMSWE. This leads to an improvement in the relative performance of some models (Reh for the decomposition step and Klu for the transposition one).

Tables 11-13 show the evolution of the model combinations presented in Table 10, from daily to yearly levels. It is worth remembering that yearly values play a key role in PV projects design and financing while the results at intermediate intervals provide useful information, for example, for performance surveillance. Finally, results coming from the control PV plants, presented in Tables 29-31 (Appendix 1), are coherent with the ones coming from the testing plants.
Table 12

Monthly metries of best and worst hourly model combinations when starting from hourly horizontal irradiation.

\begin{tabular}{llllll}
\hline Model combination & \multicolumn{2}{l}{ Static } & & & \multicolumn{2}{l}{ Double-axis tracking } \\
\cline { 2 - 3 } \cline { 5 - 6 } \cline { 5 - 6 } & MBWE & RMSWE & & MBWE & \multirow{2}{*}{ RMSWE } \\
\hline Best performing combinations & & & & \\
BRL/Per/No & -2.3 & 3.9 & & -1.7 & 4.7 \\
Erh/Bug/MRs & -1.2 & 3.2 & & -4.0 & 6.1 \\
dMh/Per/No & -3.8 & 5.2 & & -3.3 & 5.3 \\
Reh/Hay/No & -2.3 & 3.8 & & -2.9 & 5.3 \\
Worst performing combinations & & & & \\
Skh/L-J/MRs & -8.0 & 9.3 & & -14.9 & 15.3 \\
S-O/Reh/MRs & -8.0 & 9.4 & & -14.6 & 15.0 \\
\hline
\end{tabular}

\subsection{Modelling from monthly averages of daily irradiation}

Figs. 14 and 15 show the results of the ANOVA exercise applied, respectively, to the RMSWE of the yearly irradiation results and to the KSWI of the hourly intermediate values, when starting from the monthly averages of daily irradiation. Both figures only present the models of the simulation steps incorporated in this modelling path. Tables 32-37 (Appendix 1) present the numerical results of this exercise.

Again, the results obtained allow some model combinations to be defined as particularly suitable. Tables 14 and 15 present their 
Table 13

Yearly metrics of best and worst hourly model combinations when starting from hourly horizontal irradiation.

\begin{tabular}{lcclll}
\hline Model combination & \multicolumn{2}{l}{ Static } & & & \multicolumn{2}{l}{ Double-axis tracking } \\
\cline { 2 - 3 } \cline { 5 - 6 } \cline { 5 - 6 } & MBWE & RMSWE & & MBWE & \multirow{2}{*}{ RMSWE } \\
\hline Best performing combinations & & & & \\
BRL/Per/No & -2.2 & 3.0 & & -0.7 & 2.3 \\
Erh/Bug/MRs & -1.2 & 2.2 & & -2.8 & 3.3 \\
dMh/Per/No & -3.4 & 4.1 & & -2.1 & 2.7 \\
Reh/Hay/No & -2.2 & 3.0 & & -1.7 & 2.7 \\
Worst performing combinations & & & & \\
Skh/L-J/MRs & -7.6 & 8.5 & & -12.4 & 11.9 \\
S-O/Reh/MRs & -7.6 & 8.5 & & -12.2 & 11.7 \\
\hline
\end{tabular}

corresponding metrics for static and tracking structures, respectively. In each table, the three modelling paths described above (monthly average of daily irradiation, synthetic generation of irradiance series and combinations of clear and overcast sky profiles) are considered separately. Finally, the conclusions derived from these results are essentially maintained in the control population, as presented in Tables 38-43 (Appendix 1).

\section{Discussion}

\subsection{Models and simulation}

In the previous section, 31 models have been considered for the simulation of the incident irradiance in 19 locations of the Mediterranean belt. The ANOVA analysis over the different combinations allows determining the best-performing models and suggests the following comments:

1. All the models present $|M B W E|<10 \%$ and $|R M S W E|<30 \%$. Even taking into account the uncertainty associated to the original data (estimated in $3 \%$ ), they can be considered as good models according to the criteria proposed by Badescu et al [57].

2. All the models present a better performance in static structures than in tracking ones, according to the metrics proposed. This is likely derived from the larger corrections needed in the tracking case, due to larger tilted angles. Besides, longer integration periods present smaller uncertainties, as expected. This result is also applicable in the frequency domain: the distribution similarity is better for static systems, where most of the models pass the KSWI test, than for double-axis tracking ones.

3. Erh, BRL, $d M h$ and $O-H$ decomposition models perform very similarly and slightly better than Reh, $S-O$ and $S k h$ models. This behaviour is confirmed in the frequency domain and for static and tracking structures. Furthermore, to verify the validity of these results for other locations, a final comparison was carried out at

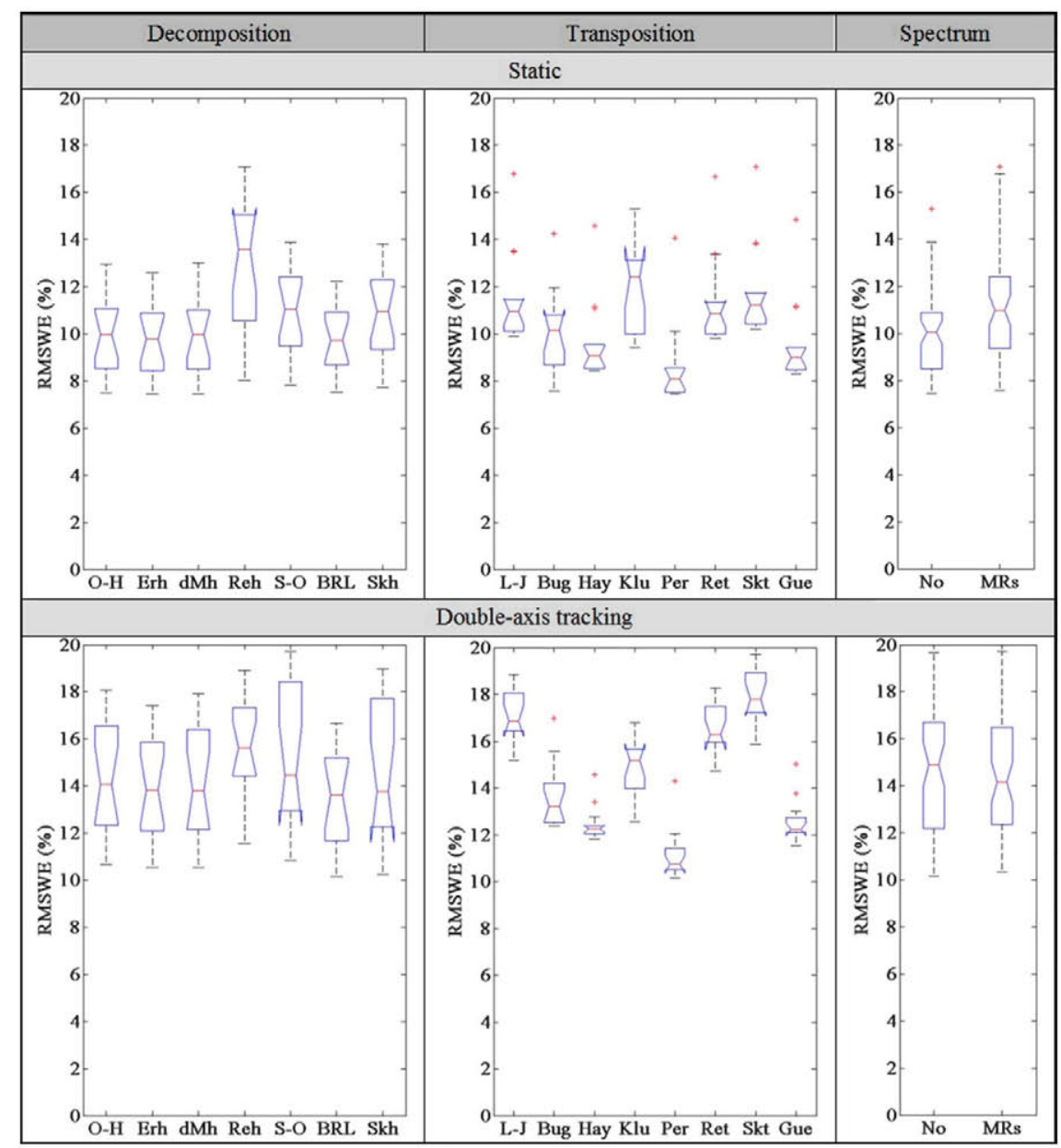

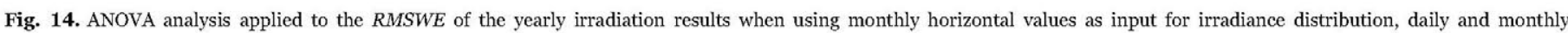
decomposition models, and for static and tracking systems, separately. 


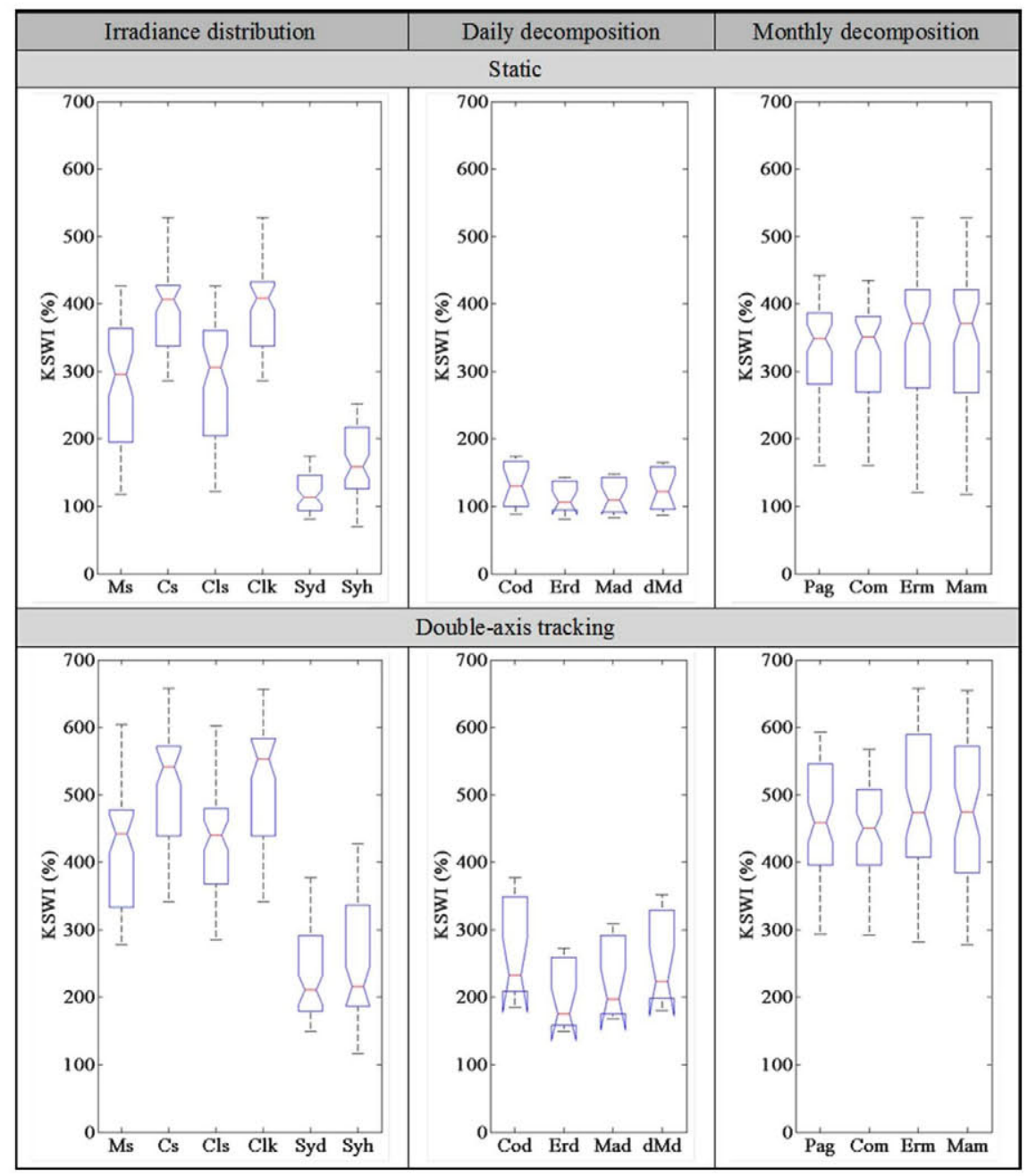

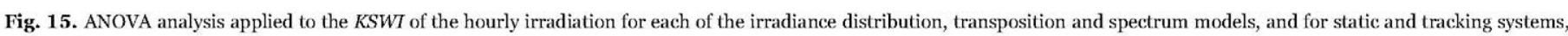
separately,

Table 14

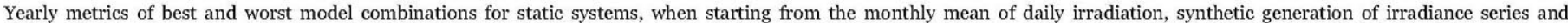
combinations of clear and overcast sky days.

\begin{tabular}{|c|c|c|c|c|}
\hline Irradiance profile & Model combination & MBWE (\%) & RMSWE (\%) & KSWI (\%) \\
\hline \multicolumn{5}{|l|}{ Best performing combinations for static structures } \\
\hline \multirow[t]{3}{*}{ Monthly average of daily irradiation } & Ms/Pam/Per/MRs & 0.5 & 2.0 & 367 \\
\hline & $\mathrm{Ms} / \mathrm{Com} / \mathrm{Gue} / \mathrm{No}$ & -1.4 & 2.4 & 243 \\
\hline & $\mathrm{Ms} / \mathrm{Erm} / \mathrm{Hay} / \mathrm{No}$ & -1.5 & 2.5 & 194 \\
\hline \multirow[t]{3}{*}{ Synthetic generation of irradiance series } & Syh/O-H/Bug/MRs & 0.2 & 1.8 & 95 \\
\hline & Syh/Skh/Khu/MRs & 0.0 & 1.9 & 118 \\
\hline & Syd/Mad/Per/MRs & -0.6 & 2.0 & 83 \\
\hline \multirow[t]{3}{*}{ Combinations of clear and overcast sky days } & $\mathrm{Cls} / \mathrm{Pam} / \mathrm{Hay} / \mathrm{No}$ & 0.0 & 1.9 & 170 \\
\hline & $\mathrm{Cls} / \mathrm{Mam} / \mathrm{Per} / \mathrm{No}$ & 0.4 & 1.9 & 127 \\
\hline & $\mathrm{Cs} / \mathrm{Com} / \mathrm{Ret} / \mathrm{No}$ & 0.0 & 1.9 & 286 \\
\hline \multicolumn{5}{|c|}{ Worst performing combinations for static structures } \\
\hline \multirow[t]{2}{*}{ Monthly average of daily irradiation } & $M s / C o m / L-J / M R s$ & -4.0 & 4.7 & 363 \\
\hline & Ms $/ P a m / S k t / M R s$ & -4.4 & 5.1 & 365 \\
\hline \multirow[t]{2}{*}{ Synthetic generation of irradiance series } & Syd/Cod/Skt/No & -5.9 & 6.7 & 174 \\
\hline & Syh/S-O/Ret/MRs & -6.4 & 7.2 & 240 \\
\hline \multirow[t]{2}{*}{ Combinations of clear and overcast sky days } & $\mathrm{Clk} / \mathrm{Com} / \mathrm{Skt} / \mathrm{No}$ & -4.3 & 5.1 & 287 \\
\hline & $\mathrm{Cls} / \mathrm{Erm} / \mathrm{Bug} / \mathrm{MRs}$ & 9.3 & 10.2 & 422 \\
\hline
\end{tabular}


Table 15

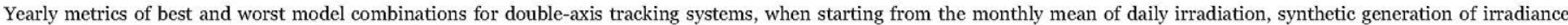
series and combinations of clear and overcast sky days.

\begin{tabular}{|c|c|c|c|c|}
\hline Irradiance profile & Model combination & MBWE (\%) & RMSWE (\%) & KSWI (\%) \\
\hline \multicolumn{5}{|l|}{ Best performing combinations } \\
\hline \multirow[t]{3}{*}{ Monthly average of daily irradiation } & $\mathrm{Ms} / \mathrm{Com} / \mathrm{Gue} / \mathrm{No}$ & 0.7 & 4.1 & 441 \\
\hline & $\mathrm{Ms} / \mathrm{Pam} / \mathrm{Klu} / \mathrm{MRs}$ & 3.0 & 4.7 & 441 \\
\hline & $\mathrm{Ms} / \mathrm{Erm} / \mathrm{Ret} / \mathrm{No}$ & -2.6 & 4.8 & 282 \\
\hline \multirow[t]{3}{*}{ Synthetic generation of irradiance series } & Syd/dMd/Klu/No & -0.2 & 3.5 & 244 \\
\hline & Syh/Erh/Bug/MRs & -0.3 & 3.6 & 166 \\
\hline & Syh/Skh/Gue/No & 0.6 & 3.9 & 188 \\
\hline \multirow[t]{3}{*}{ Combinations of clear and overcast sky days } & Clk/Pam/Per/No & 0.1 & 3.7 & 342 \\
\hline & $\mathrm{Clk} / \mathrm{Erm} / \mathrm{Hay} / \mathrm{MRs}$ & 0.2 & 3.8 & 587 \\
\hline & $\mathrm{Cls} / \mathrm{Com} / \mathrm{Skt} / \mathrm{No}$ & 3.7 & 4.8 & 459 \\
\hline \multicolumn{5}{|l|}{ Worst performing combinations } \\
\hline \multirow[t]{2}{*}{ Monthly average of daily irradiation } & Ms/Erm/Bug/MRs & 8.3 & 8.9 & 446 \\
\hline & Ms $/ \mathrm{Com} / \mathrm{Skt} / \mathrm{MRs}$ & -9.2 & 9.4 & 437 \\
\hline \multirow{2}{*}{ Synthetic generation of irradiance series } & Syd/Cod/Skt/MRs & -11.0 & 11.0 & 377 \\
\hline & Syh/S-O/L-J/MRs & -11.7 & 11.6 & 410 \\
\hline \multirow[t]{2}{*}{ Combinations of clear and overcast sky days } & $\mathrm{Cs} / \mathrm{Erm} / \mathrm{Hay} / \mathrm{MRs}$ & 13.3 & 13.3 & 578 \\
\hline & $\mathrm{Cls} / \mathrm{Mam} / \mathrm{Bug} / \mathrm{No}$ & 18.1 & 17.5 & 332 \\
\hline
\end{tabular}

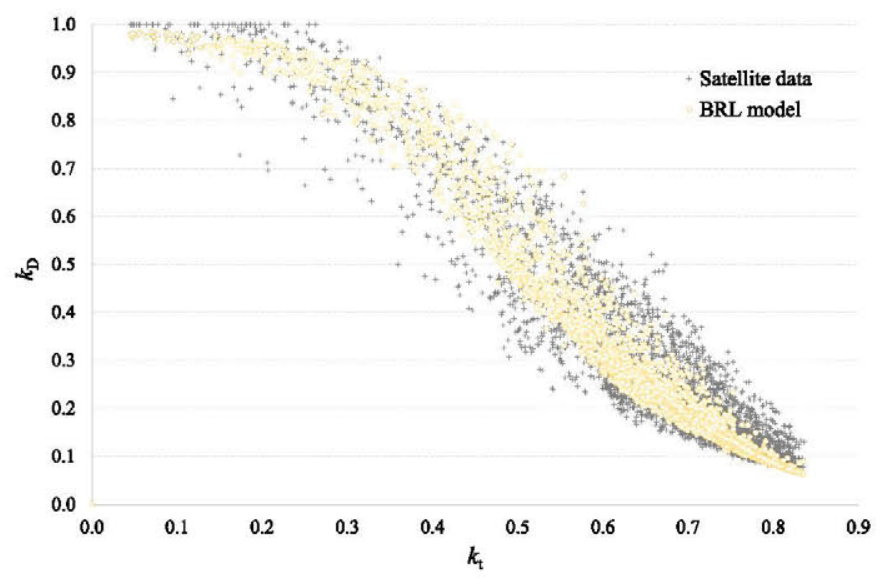

Fig. 16. Diffuse fraction versus clearness index at Puerto Libertad (Mexico). Dark crosses correspond to the satellite data provided by Solargis and light circles to the $B R L$ model simulation.

Table 16

Yearly metrics of best and worst model combinations for double-axis tracking systems, when.

\begin{tabular}{llllll}
\hline Irradiation $\left(\mathrm{MWh} / \mathrm{m}^{2}\right)$ & Satellite & O-H & Erh & BRL & $d M h$ \\
\hline$D(0)$ & 464 & 579 & 558 & 409 & 585 \\
$D_{y}$ & 553 & 682 & 658 & 504 & 689 \\
$G_{y}^{\text {ef }}$ & 3.097 & 3.026 & 3.034 & 3.113 & 3.029 \\
Difference (\%) & - & $-2,3$ & $-2,0$ & 0,5 & $-2,2$ \\
\hline
\end{tabular}

Puerto Libertad, Mexico $\left(29.97^{\circ} \mathrm{N}, 112.66^{\circ} \mathrm{W}\right)$. In this case, the experimental data were obtained from satellite images from Solargis.

Nowadays, the state of the art when requesting meteorological data includes the possibility to obtain not only the broadband horizontal
Table 18

Uncertainty in the estimation of effective in-plane irradiation when starting from broadband horizontal data.

\begin{tabular}{lll}
\hline Modelling option & Uncertainty $(\%)$ & \\
\cline { 2 - 3 } \cline { 2 - 3 } & $\begin{array}{l}\text { Static, tilt } \approx 20- \\
30^{\circ}\end{array}$ & $\begin{array}{l}\text { Double-axis } \\
\text { tracking }\end{array}$ \\
\hline Hourly $(T M Y)$ & 2.0 & 2.6 \\
Monthly average of daily irradiance & 2.3 & 4.7 \\
Synthetic generation of irradiance data & 1.9 & 3.7 \\
Combinations of clear and overcast sky & 1.9 & 3.9 \\
$\quad$ days & & \\
\hline
\end{tabular}

irradiation series but also the diffuse horizontal irradiation values, calculated through the processing of different layers of satellite images. Fig. 16 presents the relation between the diffuse fraction and the clearness index at the location when simulating with the $B R L$ model in comparison with the satellite data. Table 16 presents the results of the corresponding yearly irradiation components for the satellite data and the best-performing models. All of them present a deviation lower than the data uncertainty, with the $B R L$ model presenting an especially suitable behaviour. Other authors have found similar results $[17,58]$.

4. Interestingly, complex transposition models do not perform better than simpler ones. This is in agreement with the results obtained by other authors [12]. Per, Hay, Klu, Gue and Bug models perform better than the rest of the models, in terms of RMSWE and KSWI and for both types of structures. Again, similar results have been reported elsewhere $[16,18]$.

5. There is no significant advantage in including a spectral correction, at least when crystalline silicon PV modules are concerned. This result agrees with the findings of other authors, and seems to be

Table 17

Yearly results of the ANOVA analysis for the spectral correction models in the testing PV plants, when starting from hourly data.

\begin{tabular}{|c|c|c|c|c|c|c|}
\hline \multirow[t]{2}{*}{ Model } & \multicolumn{3}{|l|}{ Static } & \multicolumn{3}{|c|}{ Double-axis tracking } \\
\hline & $M B W E(\%)$ & RMSWE (\%) & KSWI (\%) & $M B W E(\%)$ & RMSWE (\%) & KSWI (\%) \\
\hline NoS & $-3,6$ & 4,3 & 77,1 & $-4,9$ & 5,0 & 97,2 \\
\hline RuS & $-4,8$ & 5,6 & 102,5 & $-5,6$ & 5,6 & 115,7 \\
\hline KiS & $-3,6$ & 4,3 & 82,6 & $-4,7$ & 4,9 & 88,2 \\
\hline
\end{tabular}


Table 19

Good performance model combinations used for passing from broadband horizontal to effective in-plane irradiance, depending on the modelling path.

\begin{tabular}{|c|c|c|c|c|}
\hline Modelling option & Decomposition & Transposition & Spectrum & Uncertainty (\%) \\
\hline Hourly (TMY) & BRL & Bugler & No & 1.8 \\
\hline Monthly average of daily irradiations & Page & Pérez & Martín-Ruiz & 2.0 \\
\hline Hourly synthetic generation of irradiance & Orgill-Holland & Bugler & Martín-Ruiz & 1.8 \\
\hline Combinations of clear and overcast sky days & Page & Hay & Martín-Ruiz & 1.9 \\
\hline
\end{tabular}

derived from the high variability of aerosol components in the atmosphere, which are one of the main spectrum determinants $[59,60]$. In order to verify if this result is representative of other spectral models, simulations were repeated considering the King correction (KiS) [61,62]. Table 17 presents the yearly results of the ANOVA exercise for the spectral models in the testing PV plants. Differences between the King correction and the non-correcting case are almost imperceptible.

The previous conclusions regarding the hourly decomposition, transposition and spectral models are essentially maintained when modelling from monthly average values. Besides, some particular remarks of this simulation strategy can be added:

6. The main uncertainty source is the irradiance distribution from average values. None of the models satisfied, on average, the $K-S$ test. The $K S W I$ values also indicates that the biggest influence comes from the irradiance distribution modelling, in which the synthetic generation of irradiance series is clearly the better option.

7. Different behaviour of the irradiance distribution models is observed depending on the structure type. The $\mathrm{Cs}$ and $\mathrm{Cls}$ models present a better behaviour in static structures but are disregarded for tracking systems, where $C l k, S y d$ and $S y h$ outperform the rest of the models.

8. Daily decomposition models are nearly equivalent one to another. However, Erd and Mad behave slightly better for static structures both in RMWSE and KSWI terms. For tracking systems Cod and $d M d$ present a better performance in RMSWE terms but worse in the frequency domain.

9. The impact of selecting between the monthly decomposition models proposed is almost negligible. Models present a nearly equivalent behaviour, both in RMWSE and KSWI terms.

\subsection{Modelling uncertainty}

One of the main uncertainties in the energy yield forecasting of a PV plant is that related to the pass from broadband horizontal to effective in-plane irradiation. This uncertainty is directly given by the RMSWE value obtained in the previous sections, as presented in Table 18. For each modelling path, a reference uncertainty value was obtained from the mean of the best performing model combinations, understood as those in the top $10 \%$ range. As a general comment, modelling in static structures entails between $0.6 \%$ and $1.5 \%$ less uncertainty than in tracking systems when starting from hourly values, and between $2.4 \%$ and $3.6 \%$ when modelling from monthly averages. Starting from the TMY means nearly no difference in static systems but saves between $0.9 \%$ and $2.1 \%$ uncertainty for tracking structures.

\section{Conclusions}

Passing from broadband horizontal to effective in-plane irradiance is a key step for the yield assessment of PV plants. Accomplishing this process entails different steps regarding the decomposition of the broadband irradiation, its translation to the tilted plane and its conversion to effective values. In most of the cases, it entails also the pass from monthly mean values to irradiance time series. The predictions of 544 combinations of irradiance distribution, decomposition, transposition and spectral correction models have been compared with experimental records obtained from 1 to 3 years in 19 different locations. These comparisons have been presented in terms of hourly to yearly weighted errors and frequency distribution similarity. Main conclusions are:

- Significant uncertainty differences (up to $8 \%$ ) can be achieved in function of the models chosen.

- Uncertainty is lower in static structures than in tracking systems due to smaller tilted surface angles that lead to smaller angle corrections.

- Complex models do not behave necessarily better than simpler ones, in the same way as local models do not perform systematically better than global ones.

- The spectral correction does not improve the results.

- The synthetic generation of irradiance series is the better simulation path when the TMY data is not available.

- Only when starting from the TMY data, the frequency distributions of the simulated data are statistically equivalent to the experimental data ones.

The objective of this paper was to assess the performance of some widespread models and to identify some best-performing combinations, considering the whole simulation process. Table 19 summarizes some of them for the different modelling approaches, together with their associated uncertainties.

\section{Appendix 1. Results of the ANOVA test for irradiation modelling}

\section{Hourly irradiation data}

a. Testing population

i. Hourly results (See Tables 20-22)

ii. Yearly results (See Tables 23-25)

b. Control population

i. Hourly results (See Tables 26-28)

ii. Yearly results (See Tables 29-31) 


\section{Monthly irradiation data}

a. Testing population (See Tables $32-37$ )

b. Control population (See Tables 38-43)

Table 20

Hourly results of the ANOVA analysis for the hourly decomposition models in the testing PV plants, when starting from hourly irradiation data.

\begin{tabular}{|c|c|c|c|c|c|c|}
\hline \multirow[t]{2}{*}{ Hourly decomposition } & \multicolumn{3}{|c|}{ Static (\%) } & \multicolumn{3}{|c|}{$2 \mathrm{x}$ tracking $(\%)$} \\
\hline & $M B W E$ & $R M S W E$ & KSWT & $M B W E$ & RMSWE & KSWI \\
\hline$O-H$ & -5.2 & 10.0 & 80 & -5.8 & 14.1 & 96 \\
\hline Erh & -4.8 & 9.8 & 74 & -5.1 & 13.8 & 82 \\
\hline$d M h$ & -5.2 & 10.0 & 80 & -5.8 & 13.8 & 95 \\
\hline Reh & -6.2 & 13.6 & 89 & -4.0 & 15.6 & 75 \\
\hline$S-O$ & -6.5 & 11.0 & 98 & -8.4 & 14.5 & 138 \\
\hline$B R L$ & -4.4 & 9.7 & 72 & -4.3 & 13.6 & 91 \\
\hline$S k h$ & -6.5 & 10.9 & 96 & -7.8 & 13.8 & 131 \\
\hline
\end{tabular}

Table 21

Hourly results of the ANOVA analysis for the transposition models in the testing PV plants, when starting from hourly irradiation data.

\begin{tabular}{llllllll}
\hline \multirow{2}{*}{ Transposition } & \multicolumn{2}{l}{ Static (\%) } & & & \multicolumn{2}{l}{ 2x tracking (\%) } \\
\cline { 2 - 3 } \cline { 7 - 8 } & MBWE & RMSWE & KSWI & & MBWE & RMSWE & KSWT \\
\hline L $-J$ & -7.0 & 11.0 & 101 & & -13.1 & 16.9 & 181 \\
Bug & 0.9 & 10.1 & 77 & & -1.6 & 13.2 & 85 \\
Hay & -4.4 & 9.1 & 64 & & -4.9 & 12.3 & 74 \\
Klu & 0.5 & 12.4 & 100 & -4.2 & 15.2 & 92 \\
Per & -3.0 & 8.1 & 54 & -3.2 & 10.7 & 71 \\
Ret & -6.9 & 10.9 & 98 & -12.4 & 16.3 & 168 \\
Skt & -7.4 & 11.2 & 104 & -14.0 & 17.8 & 192 \\
Gue & -4.4 & 9.0 & 64 & -5.6 & 12.2 & 81 \\
\hline
\end{tabular}

Table 22

Hourly results of the ANOVA analysis for the spectral correction model in the testing PV plants, when starting from hourly irradiation data.

\begin{tabular}{llllllll}
\hline \multirow{2}{*}{ Spectrum } & \multicolumn{2}{l}{ Static (\%) } & & & & \multicolumn{2}{l}{ 2x tracking (\%) } \\
\cline { 2 - 4 } \cline { 6 - 8 } & MBWE & RMSWE & KSWT & & MBWE & RMSWE & KSWT \\
\hline No & -3.0 & 10.1 & 77 & & -4.8 & 14.9 & 97 \\
MRs & -6.2 & 11.0 & 102 & & -7.3 & 14.1 & 116 \\
\hline
\end{tabular}

Table 23

Yearly results of the ANOVA analysis for the hourly decomposition models in the testing PV plants, when starting from hourly irradiation data.

\begin{tabular}{llllll}
\hline \multirow{2}{*}{ Hourly decomposition } & \multicolumn{2}{l}{ Static (\%) } & & \multicolumn{2}{l}{ 2x tracking (\%) } \\
\cline { 2 - 3 } & MBWE & RMSWE & & MBWE & RMSWE \\
\hline O-H & -4.1 & 4.8 & & -4.9 & 5.0 \\
Erh & -4.0 & 4.7 & & -4.7 & 4.9 \\
$d M h$ & -4.1 & 4.8 & & -4.8 & 5.0 \\
Reh & -4.5 & 5.5 & & -2.5 & 3.0 \\
$S-O$ & -5.5 & 6.2 & & -6.6 & 6.5 \\
$B R L$ & -3.9 & 4.6 & & -3.7 & 4.1 \\
$S k h$ & -5.3 & 6.1 & & -6.0 & 6.2 \\
\hline
\end{tabular}

Table 24

Yearly results of the ANOVA analysis for the transposition models in the testing PV plants, when starting from hourly irradiation data.

\begin{tabular}{llllll}
\hline \multirow{2}{*}{ Transposition } & \multicolumn{2}{l}{ Static (\%) } & & & \multicolumn{2}{l}{ 2x tracking (\%) } \\
\cline { 2 - 3 } \cline { 5 - 6 } & MBWE & RMSWE & & MBWE & RMSWE \\
\hline L-J & -6.1 & 6.9 & & -10.7 & 10.9 \\
Bug & -0.3 & 2.2 & & -1.9 & 2.8 \\
Hay & -4.2 & 4.9 & & -4.2 & 4.5 \\
Khu & -1.3 & 2.3 & & -4.3 & 4.5 \\
Per & -2.9 & 3.6 & & -1.9 & 2.8 \\
Ret & -6.0 & 6.7 & & -10.2 & 10.8 \\
Skt & -6.4 & 7.2 & & -11.8 & 11.9 \\
Gue & -4.3 & 5.0 & & -5.2 & 5.3 \\
\hline
\end{tabular}

Table 25

Yearly results of the ANOVA analysis for the spectral correction model in the testing PV plants, when starting from hourly irradiation data.

\begin{tabular}{llllll}
\hline Spectrum & \multicolumn{2}{l}{ Static (\%) } & & & \multicolumn{2}{l}{ 2x tracking (\%) } \\
\cline { 2 - 3 } \cline { 5 - 6 } & MBWE & RMSWE & & MBWE & RMSWE \\
\hline No & -3.6 & 4.3 & & -4.9 & 5.0 \\
MRs & -4.8 & 5.6 & & -5.6 & 5.7 \\
\hline
\end{tabular}

Table 26

Hourly results of the ANOVA analysis for the hourly decomposition models in the control PV plants, when starting from hourly irradiation data.

\begin{tabular}{|c|c|c|c|c|c|c|}
\hline \multirow[t]{2}{*}{ Hourly decomposition } & \multicolumn{3}{|c|}{ Static (\%) } & \multicolumn{3}{|c|}{$2 \mathrm{x}$ tracking $(\%)$} \\
\hline & $M B W E$ & RMSWE & KSWI & $M B W E$ & RMSWE & KSWI \\
\hline$O-H$ & -7.3 & 10.4 & 114 & -7.3 & 12.0 & 104 \\
\hline Erh & -7.0 & 9.9 & 106 & -6.6 & 11.8 & 87 \\
\hline$d M h$ & -7.3 & 10.5 & 113 & -7.3 & 11.9 & 105 \\
\hline Reh & -5.8 & 11.0 & 92 & -3.4 & 14.0 & 66 \\
\hline$S-O$ & -8.7 & 12.0 & 139 & -9.3 & 12.6 & 148 \\
\hline$B R L$ & -7.3 & 10.4 & 112 & -5.4 & 10.8 & 82 \\
\hline$S k h$ & -8.1 & 11.4 & 131 & -8.3 & 11.8 & 136 \\
\hline
\end{tabular}


Table 27

Hourly results of the ANOVA analysis for the transposition models in the control PV plants, when starting from hourly irradiation data.

\begin{tabular}{|c|c|c|c|c|c|c|}
\hline \multirow[t]{2}{*}{ Transposition } & \multicolumn{3}{|c|}{ Static (\%) } & \multicolumn{3}{|c|}{ 2x tracking (\%) } \\
\hline & $M B W E$ & $R M S W E$ & KSWI & $M B W E$ & RMSWE & KSWI \\
\hline$L-J$ & -10.8 & 13.9 & 155 & -14.7 & 16.3 & 190 \\
\hline Bug & -1.7 & 6.5 & 36 & -2.2 & 11.0 & 50 \\
\hline Hay & -7.0 & 9.5 & 93 & -5.9 & 10.8 & 83 \\
\hline KIu & -2.3 & 10.3 & 53 & -5.6 & 12.7 & 69 \\
\hline Per & -4.5 & 7.7 & 71 & -3.6 & 9.6 & 67 \\
\hline Ret & -10.6 & 13.6 & 150 & -14.0 & 15.7 & 178 \\
\hline$S k t$ & -11.4 & 14.4 & 162 & -15.7 & 17.1 & 203 \\
\hline Gue & -7.0 & 9.5 & 90 & -6.6 & 10.8 & 85 \\
\hline
\end{tabular}

Table 28

Hourly results of the ANOVA analysis for the spectral correction model in the control PV plants, when starting from hourly irradiation data.

\begin{tabular}{llllllll}
\hline \multirow{2}{*}{ Spectrum } & \multicolumn{2}{l}{ Static (\%) } & & & & \multicolumn{2}{l}{ 2x tracking (\%) } \\
\cline { 2 - 4 } \cline { 6 - 8 } & MBWE & RMSWE & KSWI & & MBWE & RMSWE & KSWT \\
\hline No & -6.4 & 9.7 & 72 & & -6.0 & 12.2 & 74 \\
MRs & -8.1 & 10.6 & 123 & -7.8 & 12.5 & 124 \\
\hline
\end{tabular}

Table 29

Yearly results of the ANOVA analysis for the hourly decomposition models in the control PV plants, when starting from hourly irradiation data.

\begin{tabular}{llllll}
\hline \multirow{2}{*}{ Hourly decomposition } & \multicolumn{2}{l}{ Static (\%) } & & \multicolumn{2}{l}{ 2x tracking (\%) } \\
\cline { 2 - 3 } \cline { 5 - 6 } & MBWE & RMSWE & & MBWE & \multicolumn{2}{l}{ RMSWE } \\
\hline O-H & -5.2 & 5.8 & & -5.9 & 6.3 \\
Erh & -5.2 & 5.7 & & -5.8 & 6.3 \\
$d M h$ & -5.2 & 5.8 & & -5.8 & 6.2 \\
$R e h$ & -3.8 & 4.2 & & -2.0 & 2.6 \\
$S-O$ & -5.9 & 6.5 & & -6.6 & 7.0 \\
$B R L$ & -5.3 & 5.8 & & -4.5 & 5.1 \\
$S k h$ & -5.6 & 6.2 & & -5.9 & 6.3 \\
\hline
\end{tabular}

Table 30

Yearly results of the ANOVA analysis for the transposition models in the control PV plants, when starting from hourly irradiation data.

\begin{tabular}{llllll}
\hline \multirow{2}{*}{ Transposition } & \multicolumn{2}{l}{ Static (\%) } & & & \multicolumn{2}{l}{ 2x tracking (\%) } \\
\cline { 2 - 3 } \cline { 5 - 6 } & MBWE & RMSWE & & MBWE & RMSWE \\
\hline L-J & -7.4 & 8.1 & & -11.7 & 12.6 \\
Bug & -1.7 & 1.8 & & -2.2 & 2.6 \\
Hay & -5.2 & 5.7 & & -5.0 & 5.5 \\
Klu & -2.9 & 3.3 & & -5.7 & 6.2 \\
Per & -3.4 & 3.7 & & -2.2 & 2.5 \\
Ret & -7.2 & 7.9 & & -11.2 & 12.1 \\
Skt & -7.9 & 8.6 & & -12.8 & 13.6 \\
Gue & -5.4 & 5.9 & & -5.9 & 6.3 \\
\hline
\end{tabular}

Table 31

Yearly results of the ANOVA analysis for the spectral correction model in the control PV plants, when starting from hourly irradiation data.

\begin{tabular}{llllll}
\hline Spectrum & \multicolumn{2}{l}{ Static (\%) } & & & \multicolumn{2}{l}{ 2x tracking (\%) } \\
\cline { 2 - 3 } \cline { 5 - 6 } & MBWE & RMSWE & & MBWE & RMSWE \\
\hline No & -5.2 & 5.7 & & -5.8 & 6.2 \\
MRs & -5.3 & 5.8 & & -5.8 & 6.3 \\
\hline
\end{tabular}

Table 32

Yearly results of the ANOVA analysis for the irradiance distribution models in the testing PV plants, when starting from monthly irradiation data.

\begin{tabular}{|c|c|c|c|c|c|c|}
\hline \multirow[t]{2}{*}{ Sky model } & \multicolumn{3}{|c|}{ Static (\%) } & \multicolumn{3}{|c|}{ 2x tracking (\%) } \\
\hline & $M B W E$ & RMSWE & KSWI & $M B W E$ & RMSWE & KSWI \\
\hline$M s$ & -1.5 & 3.6 & 296 & 2.8 & 5.8 & 443 \\
\hline $\mathrm{Cs}$ & 1.3 & 2.4 & 406 & 11.4 & 11.5 & 544 \\
\hline $\mathrm{Cls}$ & 0.2 & 2.1 & 306 & 8.1 & 8.4 & 441 \\
\hline$C l k$ & -3.0 & 3.9 & 409 & -2.9 & 5.2 & 555 \\
\hline Syd & -2.8 & 3.6 & 113 & -0.3 & 5.3 & 210 \\
\hline Syh & -4.0 & 4.7 & 162 & -3.1 & 4.6 & 219 \\
\hline
\end{tabular}

Table 33

Yearly results of the ANOVA analysis for the hourly decomposition models in the testing PV plants, when starting from monthly irradiation data.

\begin{tabular}{|c|c|c|c|c|c|c|}
\hline \multirow[t]{2}{*}{ Hourly decomposition } & \multicolumn{3}{|c|}{ Static (\%) } & \multicolumn{3}{|c|}{$2 \mathrm{x}$ tracking $(\%)$} \\
\hline & $M B W E$ & RMSWE & KSWI & $M B W E$ & RMSWE & KSWI \\
\hline$O-H$ & -3.9 & 4.7 & 164 & -3.3 & 4.6 & 219 \\
\hline Erh & -3.9 & 4.6 & 158 & -3.0 & 4.4 & 202 \\
\hline$d M h$ & -3.9 & 4.6 & 163 & -3.0 & 4.4 & 218 \\
\hline $\operatorname{Reh}$ & -2.8 & 3.6 & 143 & 1.6 & 5.5 & 157 \\
\hline$S-O$ & -4.5 & 5.2 & 177 & -3.7 & 5.0 & 242 \\
\hline$B R L$ & -4.0 & 4.8 & 160 & -1.6 & 4.4 & 192 \\
\hline Skh & -4.2 & 5.0 & 174 & -3.5 & 4.8 & 224 \\
\hline
\end{tabular}

Table 34

Yearly results of the ANOVA analysis for the daily decomposition models in the testing PV plants, when starting from monthly irradiation data.

\begin{tabular}{|c|c|c|c|c|c|c|}
\hline \multirow[t]{2}{*}{ Daily decomposition } & \multicolumn{3}{|c|}{ Static (\%) } & \multicolumn{3}{|c|}{ 2x tracking (\%) } \\
\hline & $M B W E$ & RMSWE & KSWI & $M B W E$ & RMSWE & KSWI \\
\hline Cod & -3.4 & 4.1 & 130 & -2.0 & 4.4 & 232 \\
\hline Erd & -2.7 & 3.5 & 106 & 1.9 & 5.5 & 174 \\
\hline $\operatorname{Mad}$ & -2.3 & 3.3 & 109 & 2.5 & 5.6 & 197 \\
\hline$d M d$ & -2.9 & 3.7 & 122 & -0.3 & 5.0 & 223 \\
\hline
\end{tabular}

Table 35

Yearly results of the ANOVA analysis for the monthly decomposition models in the testing PV plants, when starting from monthly irradiation data.

\begin{tabular}{|c|c|c|c|c|c|c|}
\hline \multirow[t]{2}{*}{ Monthly decomposition } & \multicolumn{3}{|c|}{ Static (\%) } & \multicolumn{3}{|c|}{$2 \mathrm{x}$ tracking $(\%)$} \\
\hline & $M B W E$ & RMSWE & $K S W T$ & $M B W E$ & RMSWE & KSWI \\
\hline Pag & -0.1 & 2.8 & 349 & 5.4 & 6.8 & 457 \\
\hline Com & -0.1 & 2.9 & 351 & 4.0 & 8.0 & 449 \\
\hline $\mathrm{Erm}$ & -0.1 & 2.6 & 371 & 6.1 & 7.0 & 473 \\
\hline Mam & -0.1 & 2.7 & 371 & 5.6 & 6.8 & 474 \\
\hline
\end{tabular}

Table 36

Yearly results of the ANOVA analysis for the transposition models in the testing PV plants, when starting from monthly irradiation data.

\begin{tabular}{llllllll}
\hline \multirow{2}{*}{ Transposition } & \multicolumn{2}{l}{ Static (\%) } & & & & \multicolumn{2}{l}{ 2x tracking (\%) } \\
\cline { 2 - 3 } \cline { 7 - 8 } & MBWE & RMSWE & KSWT & & MBWE & RMSWE & KSWT \\
\hline L-J & -4.0 & 4.7 & 248 & & -4.6 & 8.3 & 389 \\
Bug & 3.1 & 3.7 & 192 & & 6.9 & 7.8 & 328 \\
Hay & -2.4 & 3.2 & 192 & & 2.4 & 4.9 & 328 \\
Klu & 0.8 & 2.1 & 245 & & 1.5 & 4.4 & 355 \\
Per & -1.0 & 2.7 & 252 & & 5.2 & 6.6 & 340 \\
Ret & -3.9 & 4.6 & 252 & & -3.8 & 7.7 & 371 \\
Skt & -4.3 & 5.1 & 250 & & -5.6 & 7.9 & 409 \\
Gue & -2.7 & 3.5 & 245 & & 1.6 & 5.1 & 355 \\
\hline
\end{tabular}


Table 37

Yearly results of the ANOVA analysis for the spectral correction model in the testing PV plants, when starting from monthly irradiation data.

\begin{tabular}{llllllll}
\hline \multirow{2}{*}{ Spectrum } & \multicolumn{2}{l}{ Static (\%) } & & & & \multicolumn{2}{l}{ 2x tracking (\%) } \\
\cline { 2 - 3 } \cline { 7 - 8 } & MBWE & RMSWE & KSWI & & MBWE & RMSWE & KSWI \\
\hline No & -1.4 & 3.2 & 211 & & 1.2 & 6.3 & 340 \\
MRs & -1.4 & 3.2 & 359 & & 1.2 & 6.3 & 442 \\
\hline
\end{tabular}

Table 38

Yearly results of the ANOVA analysis for the irradiance distribution models in the control PV plants, when starting from monthly irradiation data.

\begin{tabular}{|c|c|c|c|c|c|c|}
\hline \multirow[t]{2}{*}{ Sky model } & \multicolumn{3}{|c|}{ Static (\%) } & \multicolumn{3}{|c|}{$2 \mathrm{x}$ tracking $(\%)$} \\
\hline & $M B W E$ & RMSWE & KSWI & $M B W E$ & RMSWE & KSWI \\
\hline Ms & -1.3 & 2.3 & 358 & 3.1 & 5.1 & 538 \\
\hline Cs & 3.1 & 3.1 & 450 & 13.9 & 13.9 & 655 \\
\hline $\mathrm{Cls}$ & 0.9 & 1.1 & 375 & 8.6 & 8.8 & 543 \\
\hline$C l k$ & -3.6 & 3.7 & 457 & -3.9 & 4.9 & 662 \\
\hline Syd & -3.6 & 3.7 & 135 & -1.0 & 4.8 & 251 \\
\hline Syh & -5.2 & 5.2 & 227 & -5.0 & 5.7 & 261 \\
\hline
\end{tabular}

Table 39

Yearly results of the ANOVA analysis for the hourly decomposition models in the control PV plants, when starting from monthly irradiation data.

\begin{tabular}{|c|c|c|c|c|c|c|}
\hline \multirow[t]{2}{*}{ Hourly decomposition } & \multicolumn{3}{|c|}{ Static (\%) } & \multicolumn{3}{|c|}{$2 \mathrm{x}$ tracking $(\%)$} \\
\hline & $M B W E$ & RMSWE & KSWI & $M B W E$ & RMSWE & KSWI \\
\hline$O-H$ & -5.1 & 5.2 & 228 & -5.0 & 5.7 & 263 \\
\hline Erh & -5.2 & 5.2 & 222 & -5.0 & 5.8 & 246 \\
\hline$d M h$ & -5.0 & 5.1 & 226 & -4.6 & 5.4 & 261 \\
\hline Reh & -3.4 & 3.4 & 198 & 0.3 & 5.7 & 216 \\
\hline$S-O$ & -5.7 & 5.8 & 243 & -5.5 & 6.0 & 287 \\
\hline$B R L$ & -5.3 & 5.3 & 225 & -3.7 & 4.8 & 243 \\
\hline Skh & -5.4 & 5.5 & 238 & -5.5 & 6.0 & 270 \\
\hline
\end{tabular}

Table 40

Yearly results of the ANOVA analysis for the daily decomposition models in the control PV plants, when starting from monthly irradiation data.

\begin{tabular}{|c|c|c|c|c|c|c|}
\hline \multirow[t]{2}{*}{ Daily decomposition } & \multicolumn{3}{|c|}{ Static (\%) } & \multicolumn{3}{|c|}{$2 \mathrm{x}$ tracking $(\%)$} \\
\hline & $M B W E$ & RMSWE & KSWT & MBWE & RMSWE & KSWI \\
\hline Cod & -4.4 & 4.5 & 152 & -3.1 & 4.3 & 262 \\
\hline Erd & -3.5 & 3.6 & 124 & 0.9 & 5.9 & 219 \\
\hline Mad & -2.7 & 2.8 & 127 & 2.3 & 5.4 & 237 \\
\hline$d M d$ & -3.7 & 3.8 & 143 & -1.0 & 4.3 & 254 \\
\hline
\end{tabular}

Table 41

Yearly results of the ANOVA analysis for the monthly decomposition models in the control PV plants, when starting from monthly irradiation data.

\begin{tabular}{|c|c|c|c|c|c|c|}
\hline \multirow[t]{2}{*}{ Monthly decomposition } & \multicolumn{3}{|c|}{ Static (\%) } & \multicolumn{3}{|c|}{$2 \mathrm{x}$ tracking $(\%)$} \\
\hline & $M B W E$ & RMSWE & $K S W I$ & $M B W E$ & RMSWE & KSWI \\
\hline Pag & 0.6 & 2.6 & 383 & 5.5 & 7.1 & 552 \\
\hline $\mathrm{Com}$ & 1.0 & 2.6 & 381 & 4.8 & 8.2 & 546 \\
\hline Erm & 0.9 & 2.7 & 422 & 6.7 & 7.0 & 530 \\
\hline Mam & 0.8 & 2.6 & 422 & 6.0 & 7.1 & 530 \\
\hline
\end{tabular}

Table 42

Yearly results of the ANOVA analysis for the transposition models in the control PV plants, when starting from monthly irradiation data.

\begin{tabular}{llllllll}
\hline \multirow{2}{*}{ Transposition } & \multicolumn{2}{l}{ Static (\%) } & & & \multicolumn{2}{l}{ 2x tracking (\%) } \\
\cline { 2 - 3 } \cline { 7 - 8 } \cline { 7 - 8 } & MBWE & RMSWE & KSWI & & MBWE & RMSWE & KSWI \\
\hline \multirow{2}{*}{ L-J } & -5.2 & 6.1 & -4.7 & & -4.9 & 8.9 & -5.6 \\
Bug & 2.1 & 2.9 & 2.4 & & 8.9 & 12.8 & 6.7 \\
Hay & -3.4 & 5.1 & -2.8 & 2.9 & 7.3 & 1.3 \\
Klu & 0.4 & 4.6 & -0.8 & 2.6 & 9.7 & 0.8 \\
Per & -1.2 & 3.3 & -0.9 & 6.6 & 8.7 & 5.1 \\
Ret & -5.0 & 5.9 & -4.6 & -4.5 & 8.1 & -5.2 \\
Skt & -5.8 & 6.7 & -5.2 & -6.0 & 9.4 & -6.7 \\
Gue & -3.7 & 4.9 & -3.3 & 2.0 & 7.3 & 1.0 \\
\hline
\end{tabular}

Table 43

Yearly results of the ANOVA analysis for the spectral correction models in the control PV plants, when starting from monthly irradiation data.

\begin{tabular}{llllllll}
\hline \multirow{2}{*}{ Spectrum } & \multicolumn{2}{l}{ Static (\%) } & & & & \multicolumn{2}{l}{ 2x tracking (\%) } \\
\cline { 2 - 3 } \cline { 6 - 8 } & MBWE & RMSWE & KSWI & & MBWE & RMSWE & KSWI \\
\hline No & -2.2 & 4.9 & -2.1 & & 1.8 & 8.6 & 0.4 \\
MRs & -2.2 & 4.9 & -2.1 & & 1.8 & 8.6 & 0.4 \\
\hline
\end{tabular}

\section{References}

[1] Leloux J, Lorenzo E, García-domingo B, Aguilera J, Gueymard CA. A bankable method of assessing the performance of a CPV plant. Appl Energy 2014;118(no. April):1-11.

[2] Martínez-Moreno F, Lorenzo E, Moretón R, Narvarte L. Bankable procedures for the technical quality assurance of large scale PV plants. In: Proceedings of the 29th European photovoltaic solar energy conference and exhibition; 2015. p. 2864-9.

[3] Müller B, Hardt L, Armbruster A, Kiefer K, Reise C. Yield predictions for PV power plants: empirical validation, recent advances and remaining uncertainties. In: Proceedings of the 29th European PV solar energy conference and exhibition; 2014.

[4] Abella MA, Lorenzo E, Chenlo F. Effective irradiance estimation for PV applications. In: Proceedings of the 3rd world conference on photovoltaic energy conversion; 2003.

[5] Gueymard CA, Gustafson WT, Etringer A, Storck P. Evaluation of procedures to improve solar resource assessments: optimum use of short-term data from a local weather station to correct bias in long-term satellite derived solar radiation time series. In: Proceedings of ASES-WREF Conference; 2012.

[6] Schnitzer M, Thuman C, Johnson P. The impact of solar uncertainty on project financeability: mitigating energy risk through on-site monitoring. In: Proceedings of ASES Annu. Conference; 2012.

[7] Vignola F, Grover C, Lemon N, McMahan A. Building a bankable solar radiation dataset. Sol Energy 2012;86(8):2218-29.

[8] Bertrand C, Vanderveken G, Journée M. Evaluation of decomposition models of various complexity to estimate the direct solar irradiance over Belgium. Renew Energy 2015;74:618-26.

[9] David M, Lauret P, Boland J. Evaluating tilted plane models for solar radiation using comprehensive testing procedures, at a southern hemisphere location. Renew Energy 2013;51:124-31.

[10] Demain C, Journée M, Bertrand C. Evaluation of different models to estimate the global solar radiation on inclined surfaces. Renew Energy 2013;50:710-21.

[11] Evseev EG, Kudish AI. The assessment of different models to predict the global solar radiation on a surface tilted to the south. Sol Energy 2009;83(3):377-88.

[12] Gueymard CA, Ruiz-Arias JA. Extensive worldwide validation and climate sensitivity analysis of direct irradiance predictions from 1-min global irradiance. Sol. Energy; 2015.

[13] Ineichen P. Comparison and validation of three global-to-beam irradiance models against ground measurements. Sol Energy 2008;82(6):501-12.

[14] Jacovides CP, Tymvios FS, Assimakopoulos VD, Kaltsounides NA. Comparative study of various correlations in estimating hourly diffuse fraction of global solar radiation. Renew Energy 2006;31(15):2492-504.

[15] Khalil SA, Shaffie AM. A comparative study of total, direct and diffuse solar irradiance by using different models on horizontal and inclined surfaces for Cairo, Egypt. Renew Sustain Energy Rev 2013;27:853-63.

[16] Khalil SA, Shaffie AM. Evaluation of transposition models of solar irradiance over Egypt. Renew Sustain Energy Rev 2016;66:105-19.

[17] Palmer D, Cole IR, Betts TR, Gottschalg RInterpolating and estimating horizontal diffuse solar irradiation to provide UK-Wide coverage: Selection of the best performing models. Sol. Energy (in preparation), no. 2; 2017.

[18] Yang D. Solar radiation on inclined surfaces: corrections and benchmarks. Sol 
Energy 2016;136:288-302.

[19] Zhang J, Zhao L, Deng S, Xu W, Zhang Y. A critical review of the models used to estimate solar radiation. Renew Sustain Energy Rev 2017;70(no. November 2016):314-29.

[20] Besharat F, Dehghan AA, Faghih AR. Empirical models for estimating global solar radiation: a review and case study. Renew Sustain Energy Rev 2013;21:798-821.

[21] Hu Y, Zhang J, Cao W, Wu J, Tian GY, Finney S, Kirtley J. Online two-section PV array fault diagnosis with optimized voltage sensor locations. IEEE Trans Ind Electron 2015;46, [no. c, pp. 1-1].

[22] Despotovic M, Nedic V, Despotovic D, Cvetanovic S. Evaluation of empirical models for predicting monthly mean horizontal diffuse solar radiation. Renew Sustain Energy Rev 2016;56:246-60.

[23] Jamil B, Akhtar N. Comparison of empirical models to estimate monthly mean diffuse solar radiation from measured data: case study for humid-subtropical climatic region of India. Renew Sustain Energy Rev 2017(no. November 2016):1-17.

[24] Khorasanizadeh H, Mohammadi K, Goudarzi N. Prediction of horizontal diffuse solar radiation using clearness index based empirical models; A case study. Int $J$ Hydrog Energy 2016;41(47):21888-98.

[25] Khorasanizadeh $\mathrm{H}$, Mohammadi K. Diffuse solar radiation on a horizontal surface: reviewing and categorizing the empirical models. Renew Sustain Energy Rev 2016;53:338-62.

[26] Abbas S, Maleki M, Hizam H, Gomes C. Estimation of hourly, daily and monthly global solar radiation on inclined surfaces: models re-visited. Energies 2017;10(134).

[27] Yadav AK, Chandel SS. Tilt angle optimization to maximize incident solar radiation: a review. Renew Sustain Energy Rev 2013;23:503-13.

[28] Fraunhofer ISE. Photovoltaics Report; 2015.

[29] Orgill JF, Hollands KGT. Correlation equation for hourly diffuse radiation on a horizontal surface. Sol Energy 1977;19(4):357-9.

[30] Erbs DG, Klein SA, Duffie JA. Estimation of the diffuse radiation fraction for hourly, daily, and monthly-average global radiation. Sol Energy 1982;28(4):293-302.

[31] De Miguel A, Bilbao J, Aguiar R, Kambezidis H, Negro E. Diffuse solar irradiation model evaluation in the North Mediterranean belt area. Sol Energy 2001;70(2):143-53.

[32] Reindl DT, Beckman W, Duffie J. Diffuse fraction correlations. Sol Energy 1990;45(1):1-7.

[33] Skartveit A, Olseth JA. A model for the diffuse fraction of hourly global radiation. Sol Energy 1987;38(4):271-4.

[34] Skartveit A, Olseth JA, Tuft ME. An hourly diffuse fraction model with correction for variability and surface albedo. Sol Energy 1998;63(3):173-83.

[35] Ridley B, Boland J, Lauret P. Modelling of diffuse solar fraction with multiple predictors. Renew Energy 2010;35(2):478-83.

[36] Liu BYH, Jordan RC. The interrelationship and characteristic distribution of direct, diffuse and total solar radiation. Sol Energy 1960;4(3):1-19.

[37] Bugler JW. The determination of hourly insolation on an inclined plane using a diffuse irradiance model based on hourly measured global horizontal insolation. Sol Energy 1977;19(5):477-91.

[38] Hay JE, Davies JA. Calculation of the solar radiation incident on an inclined surface. In: Proceedings of the First Canadian Solar Radiation Data Workshop; 1980.

[39] Klucher TM. Evaluation of models to predict insolation on tilted surfaces. Sol Energy 1979;23:111-4.

[40] Perez R, Stewart R, Arbogast C, Seals R, Scott J. An anisotropic hourly diffuse radiation model for sloping surfaces: description, performance validation, site dependency evaluation. Sol Energy 1986;36(6):481-97.
[41] Reindl DT, Beckman W, Duffie J. Evaluation of hourly tilted surface radiation models. Sol Energy 1990;45(1):9-17.

[42] Skartveit A, Olseth JA. Modelling slope irradiance at high latitudes. Sol Energy $1986 ; 36(4): 333-44$

[43] Gueymard CA. An anisotropic solar irradiance model for tilted surfaces and its comparison with selected engineering algorithms. Sol. Energy 1987;38(5):367-86

[44] Martín N, Ruiz JM. Annual angular reflection losses in PV modules. Prog Photovolt Res Appl 2005;13(1):75-84.

[45] Martín N, Ruiz JM. A new method for the spectral characterisation of PV modules. Prog Photovolt Res Appl 1999;7(4):299-310.

[46] NREL. Swera, National Renewable Energy Laboratory. [Online]. Available: 〈https://maps.nrel.gov/swera〉; 2016.

[47] JRC-EU. PVGIS, Joint Research Center, European Commission. [Online]. Available: (re.jrc.ec.europa.eu/pvgis); 2016.

[48] Collares-Pereira M, Rabl A. The average distribution of solar radiation-correlations between diffuse and hemispherical and between daily and hourly insolation values. Sol Energy 1979;22(2):155-64.

[49] Page JK. The estimation of monthly mean values of daily short wave irradiation on vertical and inclined surfaces from sunshine records for latitudes $60^{\circ} \mathrm{N}$ to $40^{\circ} \mathrm{S}$; 1976.

[50] Macagnan M, Lorenzo E, Jiménez C. Solar Radiation in Madrid. Int J Sol Energy 1994;16(1):1-14.

[51] Aguiar R, Collares-Pereira M, Conde JP. Simple procedure for generating sequences of daily radiation values using a library of Markov transition matrices. Sol Energy 1988;40(3):269-79.

[52] Aguiar R, Collares-Pereira M. TAG: a time-dependent, autoregressive, Gaussian model for generating synthetic hourly radiation. Sol Energy 1992;49(3):167-74

[53] Rigollier C, Bauer O, Wald L. On the clear sky model of the ESRA - European solar radiation atlas - with respect to the heliosat method. Sol Energy 2000;68(1):33-48.

[54] Polo J, Zarzalejo LF, Ramirez L, Espinar B. Iterative filtering of ground data for qualifying statistical models for solar irradiance estimation from satellite data. Sol Energy 2006;80(3):240-7.

[55] Espinar B, Ramírez L, Drews A, Beyer HG, Zarzalejo LF, Polo J, Martín L. Analysis of different comparison parameters applied to solar radiation data from satellite and German radiometric stations. Sol Energy 2009;83(1):118-25.

[56] Carey G. Multivariate analysis of variance (MANOVA II : Practical guide to ANOVA and MANOVA for SAS terminology for ANOVA. Analysis 1998:1-14.

[57] Badescu V, Gueymard CA, Cheval S, Oprea C, Baciu M, Dumitrescu A, Iacobescu F, Milos 1, Rada C. Accuracy and sensitivity analysis for 54 models of computing hourly diffuse solar irradiation on clear sky. Theor Appl Climatol 2013;111(34):379-99.

[58] Lemos LFL, Starke AR, Boland J, Cardemil JM, Machado RD, Colle S. Assessment of solar radiation components in Brazil using the BRL model. Renew Energy 2017;108.

[59] Marion B. Preliminary investigation of methods for correcting for variations in solar spectrum under clear skies; 2010.

[60] Osterwald CR, Emery KA, Muller M. Photovoltaic module calibration value versus optical air mass: the air mass function. Prog Photovolt Res Appl 2014;22(5):560-73.

[61] King DL, Kratochvil JA, Boyson WE, Measuring solar spectral and angle-ofincidence effects on photovoltaic modules and solar irradiance sensors. In: Proceedings of Conference Rec. Twenty Sixth IEEE Photovolt. Spec. Conference 1997; 1997. pp. 1113-6.

[62] King DL, Kratochvil Ja, Boyson WE. Photovoltaic array performance model, Online, vol. 8, no. December; 2004. pp. 1-19. 